\title{
Selective and Highly Efficient Adsorption of a Mixture of Anionic and Cationic Dyes as Synthetic Wastewater Absorbents on Layered Double Hydroxide: Experimental and Computational Studies
}

Rehab K. Mahmoud

Beni-Suef University

Mohamed Taha

Beni-Suef University

Amal Zaher

Beni-Suef University

Rafat M. Amin ( $\square$ rafatamin@yahoo.com )

Beni-Suef University

\section{Research Article}

Keywords: Zn-Fe LDH, Dyes, Adsorption, Selectivity, Isotherm, Degradation

Posted Date: June 25th, 2021

DOl: https://doi.org/10.21203/rs.3.rs-640132/v1

License: (c) (i) This work is licensed under a Creative Commons Attribution 4.0 International License.

Read Full License 


\title{
Selective and Highly Efficient Adsorption of a Mixture of Anionic and Cationic Dyes as Synthetic Wastewater Absorbents on Layered Double Hydroxide: Experimental and Computational Studies
}

\author{
Rehab K. Mahmoud ${ }^{\mathrm{a}}$, Mohamed Taha ${ }^{\mathrm{b}}$, Amal Zaher ${ }^{\mathrm{c}}$, Rafat M. Amin ${ }^{\mathrm{d}, *}$ \\ ${ }^{a}$ Department of Chemistry, Faculty of Science, Beni-Suef University, 62511 Beni-Suef, Egypt \\ ${ }^{b}$ Materials Science and Nanotechnology Department, Faculty of Postgraduate Studies for \\ Advanced Sciences (PSAS), Beni-Suef University, Beni-Suef, Egypt \\ ${ }^{\mathrm{c}}$ Environmental Science and Industrial Development Department, Faculty of Postgraduate \\ studies for Advanced Sciences, Beni-Suef University, Beni-Suef, Egypt \\ ${ }^{d}$ Department of Physics, Faculty of Science, Beni-Suef University, 62511 Beni-Suef, Egypt \\ Corresponding authors: \\ E-mail addresses: rafatamin@yahoo.com (Rafat M. Amin)
}

\begin{abstract}
Background: In the current work, the removal of cationic and anionic dyes from water was studied both experimentally and computationally. We examine the selectivity of the adsorbent, $\mathrm{Zn}-\mathrm{Fe}$ layered double hydroxide (LDH) toward three cationic and anionic dyes.

Methods: The chemical and physical properties of the prepared adsorbent before and after adsorption were investigated using FT-IR, X-ray diffraction, zeta potential, energy dispersive Xray, X-ray photoelectron spectroscopy, particle size, HRTEM, and FESEM analysis; optical and electric properties were estimated. The influence of $\mathrm{pH}$ on the adsorption process was estimated. Monte Carlo simulations were performed to understand the adsorption mechanism and compute the adsorption energies.

Significant Findings: Single dye adsorption tests revealed that Zn-Fe LDH effectively takes up anionic methyl orange (MO) more than the cationic dyes methylene blue (MB) and malachite green (MG). From MO/MB/MG mixture experiments, LDH selectively adsorbed in the following order: $\mathrm{MO}>\mathrm{MB}>\mathrm{MG}$. The adsorption capacity of a single dye solution was 230.68 , 133.29, and $57.34 \mathrm{mg} / \mathrm{g}$ for $\mathrm{MO}, \mathrm{MB}$, and $\mathrm{MG}$, respectively; for the ternary solution, the adsorption capacity was 217.97, 93.122, and $49.57 \mathrm{mg} / \mathrm{g}$ for MO, MB, and MG, respectively. $\mathrm{Zn}-\mathrm{Fe} \mathrm{LDH}$ was also used as a photocatalyst, giving $92.2 \%$ and $84.7 \%$ degradation at concentrations of 10 and $20 \mathrm{mg} / \mathrm{L}$, respectively.
\end{abstract}


Keywords: Zn-Fe LDH, Dyes, Adsorption, Selectivity, Isotherm, Degradation

\section{Introduction}

The textile industry is characterized by the consumption of large quantities of water, much of which contains dyes [1]. There are many industries that use dyes, such as the paper, plastics, and leather tanning industries [2]. The effluent discharge of the textile industry leads to environmental pollution owing to the existence of complex mixtures of methylene green (MG), methyl orange (MO), and malachite blue (MB) as cationic and anionic dyes [3] and toxic metal ions in polluted water [4]. The usage of dyes has a hazardous effect on all life forms, that is, humans, plants, and animals; therefore, their effective disposal is necessary [5]. Thus, different chemical and physical techniques have been applied, such as biodegradation, reverse osmosis, activated sludge, chemical oxidation, and electrochemical methods involving membrane separation, chemical oxidation, anaerobic and aerobic microbial degradation, adsorption, and photodegradation [6-8].

The adsorption process is thought to be more efficient when compared with other physicochemical wastewater treatment techniques [8-12]. Activated carbon, which is widely used as an adsorbent for wastewater treatment, is expensive and therefore, uneconomical [13]. The removal of organic pollutants with the use of layered double hydroxide (LDH) has been of great interest to many researchers in recent years. This is because of its unique features and properties, such as high surface area, low toxicity, low cost, high capacity of anion substitution, recoverability, and high stabilities for chemical and thermal properties [14]. Several techniques have been reported for the modification of LDHs, for example, the reconstruction process, the ion exchange process, and coprecipitation in the presence of organics [15]. Many limitations of LDHs still exist, including the fact that they cannot be applied to a highly acidic or basic medium. The challenge is the preparation of LDH materials by applying new techniques and using advanced modifications, environmentally friendly methods, and easy operation. In our study, we selected $\mathrm{Zn}-\mathrm{Fe} \mathrm{LDH}$ as a model over other LDHs owing to its high stability constant at nearly 25.27 and low solubility product reach of 62.51 [16]. Furthermore, increasing amounts of solid adsorbent wastes require the development of new recycling methods. This is a critical requirement around the world [17].

The study of the characteristic optical properties of a material is important in providing data regarding electronic transitions, fundamental gaps, localized states, and trapping levels. 
Absorption of visible light from the top of the valence band (which is mainly composed of oxygen (O) $2 \mathrm{p}$ orbitals hybridized with $\mathrm{Fe}$ or $\mathrm{Zn} 3 \mathrm{~d}$ orbitals) to the bottom of the conduction band (which is mainly composed of Fe or $\mathrm{Zn} 3 \mathrm{~d}$ orbitals hybridized with $\mathrm{O} 2 \mathrm{p}$ orbitals) is the reason for the electronic band gap transition [18].

The process of degradation has been recommended as an effective environmental strategy for remediating organic pollutants such as dyes, especially when using low-cost semiconducting metal oxides as photocatalysts [19, 20]. Therefore, after an experimental study of the adsorption process, we examined the LDH applied as a photocatalyst for the MO dye. In this study, we aim to analyze a multiadsorbate system by studying the selectivity of the main dye in the ternary system and then the interaction and behavior of two model cationic dyes (MB and MG) and one model anionic dye, MO [21], with Zn-Fe LDH applied as an effective adsorbent material. The $\mathrm{Zn}-\mathrm{Fe}$ LDH prepared was well characterized by FT-IR, XRD, FESEM, HRTEM, UV-Vis spectroscopy, $\mathrm{N}_{2}$ adsorption/desorption, zeta potential, partial size analysis, and XPS. The adsorption mechanism of the electrical behavior was analyzed. This study highlights the potential application of $\mathrm{Zn}-\mathrm{Fe} \mathrm{LDH}$ as an efficient adsorbent of anionic and cationic dyes and its electrical properties, which extend its scope for application in environmental remediation processes.

\section{Experimental Details}

\subsection{Materials}

$\mathrm{Zn}\left(\mathrm{NO}_{3}\right)_{2} \cdot 6 \mathrm{H}_{2} \mathrm{O}$ was purchased from Chem-Lab NV, Belgium, $\mathrm{Fe}\left(\mathrm{NO}_{3}\right)_{3} .9 \mathrm{H}_{2} \mathrm{O}$. Hydrochloric acid was supplied by Carlo Erba reagent while $\mathrm{NaOH}$ was supplied from Piochem for laboratory chemicals, EGYPT. MB, MO and MG powder were purchased from Oxford laboratory reagents (India) Table 1. All mentioned chemicals had been used without any purification. The experiments and preparation of the material were performed using deionized water which free from $\mathrm{CO}_{2}$.

Table 1 Chemicals and physical characteristics of methylene blue, methyl orange and malachite green.

\begin{tabular}{llll}
\hline Dye name & Methelene blue [26] & Methyl orange & Malachite green \\
& & {$[24,25]$} & {$[23]$} \\
\hline Appearance & Dark green crystals or & Orange-yellow & Green crystalline \\
\hline
\end{tabular}




\begin{tabular}{llll}
\hline & powder & powder & powder \\
Molecular formula & $\mathrm{C}_{16} \mathrm{H}_{1}{ }_{8} \mathrm{~N}_{3} \mathrm{SCl}$ & $\mathrm{C}_{14} \mathrm{H}_{14} \mathrm{~N}_{3} \mathrm{NaO}_{3} \mathrm{~S}$ & $\mathrm{C}_{23} \mathrm{H}_{25} \mathrm{ClN}_{2}$ \\
Molecular weight $(\mathrm{g} / \mathrm{mol})$ & 319.85 & 327.33 & 364.9 \\
Density $\left(\mathrm{g} / \mathrm{cm}^{3}\right)$ & 0.98 & 1.28 & 1.044 \\
$\lambda \max (\mathrm{nm})$ & 660 & 464 & 616.9 \\
\multicolumn{1}{c}{ Type of dye } & Cationic & Anionic & Cationic \\
\hline
\end{tabular}

\subsection{Synthesis of $\mathrm{Zn}-\mathrm{Fe} \mathrm{LDH}$}

In our work Co-precipitation method was used to prepare $\mathrm{Zn}-\mathrm{Fe} \mathrm{LDH}$. The added solution of Zinc and iron as nitrate precursors by 4:1 molar ratio. Slow flow rate $0.10 \mathrm{ml} / \mathrm{min}$ of $\mathrm{NaOH}(2 \mathrm{M})$ solution was added till $\mathrm{pH} 10$ for completes the precipitation. The resulting material was aged and kept at $60 \pm 0.5^{\circ} \mathrm{C}$ for $12 \mathrm{hr}$ and then was filtered and washed several times using distilled water to get rid of excess $\mathrm{OH}^{-}$and then washing using ethanol. Finally, the resulted adsorbent sample had been dried at $80 \pm 0.5^{\circ} \mathrm{C}$ for $24 \mathrm{hr}$ [22].

\subsection{Characterizations of the prepared material}

The formed LDH/nitrate type had been characterized by XRD (PANalytical Empyean, Sweden). Accelerating voltage used was $40 \mathrm{KV}, 30 \mathrm{~mA}$ current, ranging from 5 to $60^{\circ}$ scan angle and scan step of $0.05^{\circ}$. To determine the vibration of chemical bonds, Bruker (vertex 70 FTIR-FT Raman) Germany spectrophotometry (serial number 1341) covering frequency range of $400-4000 \mathrm{~cm}^{-1}$ had been applied and using potassium bromide disc. The morphology of materials had been estimated by Field Emission Scanning Electron Microscope (FESEM) Germany. The EDAX ( Quanta FEG250, Germany) had been used to determine the molar ratio of Zn-Fe LDH. The BET specific pore volume, specific surface area and pore size distribution of the Nanoadsorbents were determined by $\mathrm{N}_{2}$ adsorption applying an automatic surface analyzer (TriStar II 3020, Micrometrics, USA). For analyze the elemental composition of the prepared material (Kratos-England), the X-ray photo electron spectroscopy (XPS) with Al-KaX-ray mono chromatic source $(\mathrm{hv}=1486.6 \mathrm{eV})$ had been used. Zeta potential and hydrodynamic particle size were investigated by Nano-Zeta sizer (Malvern Instruments Ltd, United Kingdom). Using highresolution transmission electron microscopy (HRTEM, JEOL-JEM 2100) to determine the microstructures of the used $\mathrm{LDH}$. The procedure of sample preparation for zeta potential measurements was as explained in our previous work [14] 


\subsection{Investigation of optical properties}

The optical band gap of the sample material was performed with the Kubelka-Munk (K-M) function using the following equation [23]:

$F(R)=\frac{(1-R)^{2}}{2 R}=\frac{K(\lambda)}{S(\lambda)}$,

where $F(R), R, K(\lambda)$, and $S(\lambda)$ are the $\mathrm{K}-\mathrm{M}$ or re-emission functions, the diffuse reflectance of the sample, the absorption coefficient, and the scattering coefficient, respectively.

The absorption coefficient $\alpha$ was calculated using the Lambert Law from the measured absorbance results [24, 25]:

$\alpha=2.303 \mathrm{~A} / \mathrm{d}$.

The following expression, suggested by Tauc, Davis, and Mott, is used:

$(\alpha h v)^{1 / n}=A\left(h v-E_{g}\right)$.

It can be equal to $1 / 2,2,3 / 2$, or 3 for directly allowed, indirectly allowed, forbidden direct, and forbidden indirect transitions, respectively. In this case of direct transitions of $\mathrm{Zn}-\mathrm{Fe} \mathrm{LDH}$ nanoparticles, the value of $n$ is equal to $1 / 2$.

The acquired diffuse reflectance spectrum is converted to the Kubelka-Munk function. The vertical axis is then converted to the quantity $F\left(R_{\infty}\right)$, which is proportional to $\alpha$. The $\alpha$ is substituted by $F\left(R_{\infty}\right)$ in the Tauc equation. Thus, the relational expression in the experiment becomes

$\left(h v F\left(R_{\infty}\right)\right)^{2}=A\left(h v-E_{g}\right)$.

\subsection{Dielectric properties}

The dielectric behavior of $\mathrm{Zn}-\mathrm{Fe}$ LDH samples as a function of frequency was studied in the form of the dielectric constant, dielectric loss, and the ac conductivity $\left(\sigma_{a c}\right)$ at different temperatures, including the effect of gamma irradiation on it. The dielectric properties of the nanoparticles are studied using a HIOKI 3532 LCR HI-TESTER in the frequency region from $200 \mathrm{~Hz}$ to $5 \mathrm{MHz}$. The nanoparticles are made into pellets, and the surfaces of the samples were coated with a silver paste and placed between the two copper electrodes that act as a parallel plate condenser.

The dielectric constant $\left(\varepsilon^{\prime}\right)$ of the material is measured by using the formula

$\varepsilon^{\prime}=\frac{C d}{A \varepsilon_{0}}$.

\subsection{Adsorption study}


Several experiments were performed to obtain data regarding the influence of the solution $\mathrm{pH}$, adsorbent amount, initial dye concentration, and the selectivity of LDH toward applied dyes. Falcon tubes $(50 \mathrm{~mL})$ contained $0.05 \mathrm{~g}$ of the synthesized adsorbent and $20 \mathrm{ppm}$ of dye as a pollutant. The $\mathrm{pH}$ of the dye solution was adjusted from 3-10 using $\mathrm{HCl}$ or $\mathrm{NaOH}(0.10 \mathrm{~N})$, and measurements were made with a Metrohm 751 Titrino $\mathrm{pH}$ meter. The adsorption steps were performed for two other dyes. All experiments took place in the dark, and the Falcon tubes were put on an orbital shaker (SO330-Pro) for $20 \mathrm{~h}$ at $250 \mathrm{rpm}$ until reaching equilibrium. A UV-Vis spectrophotometer (UV-2600, Shimadz, Japan) was used to estimate the residual concentration of each dye at a wavelength of 675, 464, and $618 \mathrm{~nm}$ for MB, MO, and MG, respectively [26]. To check reproducibility, all experiments were performed in triplicate. Upon estimating the $\mathrm{pH}$ of each dye, a pH value of 9 was estimated for MB, 6 for MO, and 5.4 for MG; and the effect of the initial dye concentrations was determined for each dye by adding $0.05 \mathrm{~g}$ of catalyst to $50 \mathrm{~mL}$ of the dye solution. After each adsorption process, syringe filters (Millipore Millex-G, $0.22 \mu \mathrm{m}$ pore size) were used to separate the catalyst from the solution. Uptake experiments were performed in batch mode to estimate the effects of the initial concentration of $\mathrm{MB}$ and the other competing dyes (MO and MG). The amount of dye removed is estimated by:

$q_{e}=\left(C_{o}-C_{t}\right) \times V / W$

$\% Q=\left(C_{o}-C_{t}\right) \times 100 / C_{o}$.

Equilibrium conditions were investigated by isotherm models and discussed in terms of nonlinear equations. We demonstrated the significance of our results using the statistical parameters $\mathrm{R}^{2}$ and $\chi^{2}$ :

$\chi^{2}=\sum(q \exp -q c a l)^{2} / q c a l^{2}$

Sun-light driven photocatalytic dye degradation was applied in the experiments. The photodegradation of Methyl orange dye was performed by using a photocatalytic glass reactor containing of a cylindrical glass tube. The experiments were happened in Sunlight between 11 AM-3 PM when the sunlight intensity had been nearly constant with low variation. The experimental procedures of the included degradation tests were happened by mixing definite amounts of the LDH as photocatalyst with MO dye solution in the dark for about $24 \mathrm{~h}$ as a step to achieve the dye adsorption/desorption equilibrium state. After that, the photocatalytic activity happened in the visible light. The photodegradation parameters (dosage $(10 \mathrm{mg})$, concentration (10 and $20 \mathrm{mg} / \mathrm{L}$ ), $\mathrm{pH}(\mathrm{pH} 7$ ), and contact time (to $240 \mathrm{~min}$ )) after adjusting the tested volume at 
about $50 \mathrm{~mL}$ and the reaction temperature $35^{\circ} \mathrm{C}$. At the end of experiment, $\mathrm{LDH}$ particles were separated from the solutions by centrifugation and the residual concentrations of MO dyes was estimated.

\subsection{Consistency of results and quality assurance}

The remaining concentration of the dye in samples was recorded using a UV-Vis spectrophotometer. The plastic and glassware used in the research experiments were cleaned and washed with $5 \% \mathrm{HCl}$ aqueous solution and then immersed in bidistilled water. All chemicals used in the research experiments were of high grade, and the precision in dye records was determined by consecutively inserting each dye solution standard into the UV-Vis spectrophotometer to get a calibration curve $\left(R^{2}=0.999\right)$. After every 15 samples, 3 standard solutions of dye were run to confirm the reliability of data from the spectrophotometer. All experiments were performed in triplicate to ascertain reproducibility, and the average concentration was estimated by applying the mean and standard deviation $( \pm \mathrm{SD})$ obtained from SPSS version 16 . A p-value of less than 0.05 was taken to be statistically significant.

\subsection{Monte Carlo (MC) simulation}

The MC simulation was performed by the BIOVIA Materials Studio 2017 package. The Zn-Fe LDH models were built from the crystal structure of hydrotalcite $\left[\mathrm{Mg}_{3} \mathrm{Al}(\mathrm{OH})_{8}\right]$. The $\mathrm{Mg}^{2+}$ and $\mathrm{Al}^{3+}$ cations were replaced by $\mathrm{Zn}^{2+}$ and $\mathrm{Fe}^{3+}$ cations, respectively. The cell formula was $\mathrm{Zn}_{20} \mathrm{Fe}_{5}$ $(\mathrm{OH})_{50}\left(\mathrm{NO}_{3}\right)_{5}$, and the cations distribution was adopted as reported by Fan et al. [27] for the 4 $\left(\mathrm{M}^{2+} / \mathrm{M}^{3+}\right)$ molar ratio. The cell and the studied dyes were optimized using the Universal forcefield [43], and the QEq charge method [28] was applied. The optimization process was done by the Forcite module. The convergence tolerance quality was set to be ultra-fine.

The adsorption of MO, MB and MG molecules on the Zn-Fe LDH surface was carried out using MC simulation, by using the adsorption locator module that uses the Metropolis MC method to obtain the lowest-energy conformers between the adsorbate and adsorbent surface. This module calculates ( $\left.\Delta E_{\text {ads }}\right)$. Two surfaces were cleavage from the optimized constructed cell, that is, LDH (001) and (010) surfaces. A $35 \AA$ A-thick vacuum slab above the LDH surfaces was created, and the two models are shown Fig. 1. As shown in this figure, the (001) and (010) planes represent the hydroxyl, and Zn-Fe LDH facets, respectively. The van der Waals force and electrostatic interaction were handled by the atom-based and Ewald methods, respectively. 


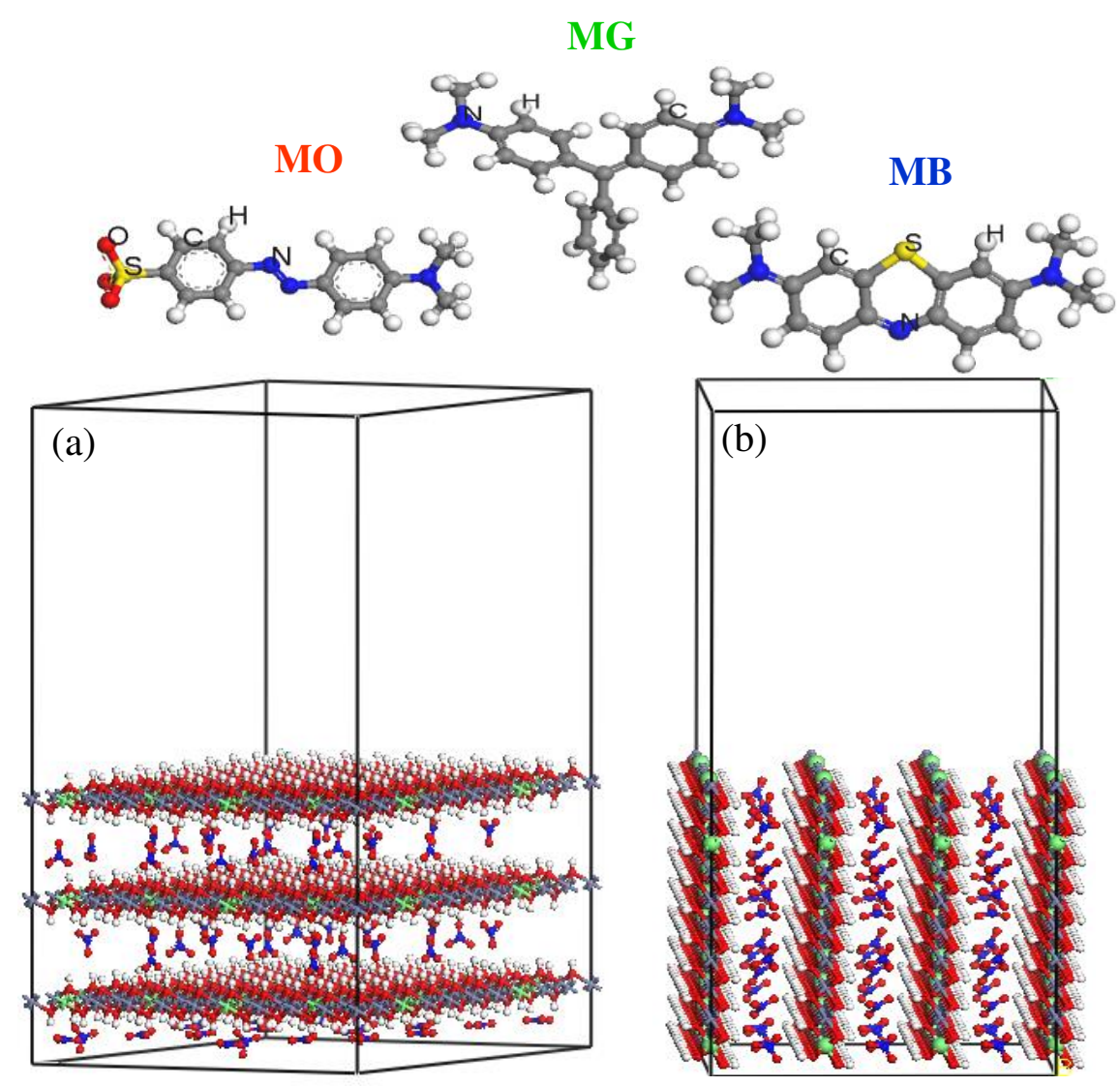

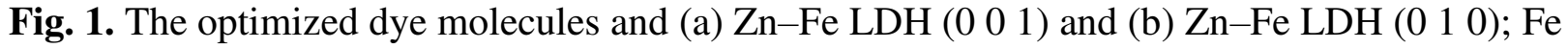
atoms (cyan), $\mathrm{Zn}$ atoms (violet), $\mathrm{O}$ atoms (red), $\mathrm{N}$ atoms (blue), $\mathrm{H}$ atoms (white).

\section{Results and discussion}

\subsection{Morphology study}

FESEM images were applied to perform the morphology of the synthesis LDH as shown in Fig.2 (a-d). It displayed characteristic sheets, layers and hexagonal like morphology of LDH. Using precipitation technique for preparation of the adsorbent may be the reason of the layers accumulation in this statue and also the reaction rate and time have been an important role on the thickness and shape of prepared sample. It could be due to the slow nucleation for precipitate formation [29]. EDX analysis was performed to confirm the presence of $\mathrm{Zn}, \mathrm{Fe}$ and $\mathrm{O}$ as seen in Fig. 2e. 

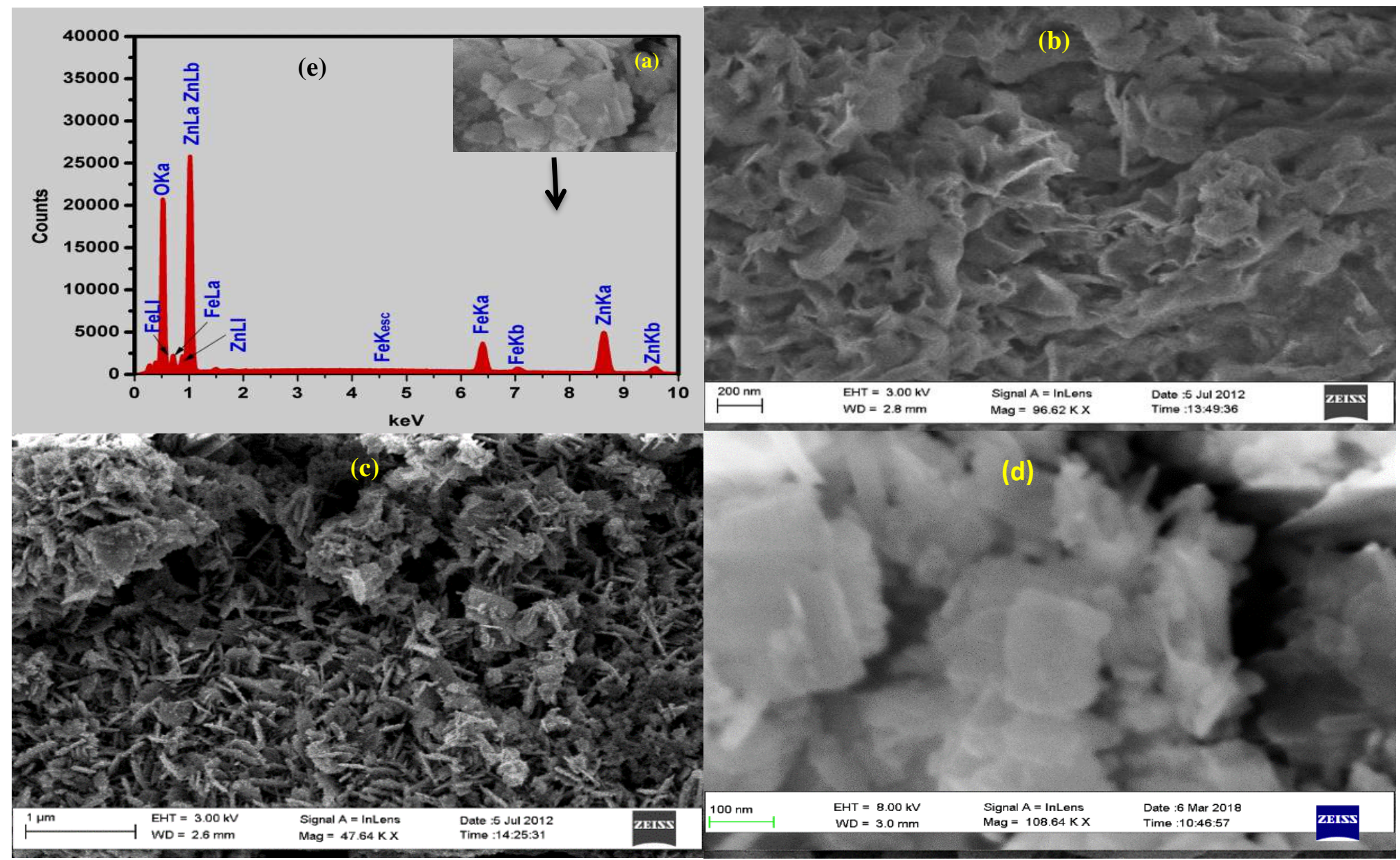

Fig. 2. FESEM images of the prepared Zn-Fe LDH (a-d); and EDX (e ).

Overall, these results confirm the efficiency of the preparation method used in the synthesis of layer structure from the nano-particulate morphology. As shown in Fig. 3(a-d) (HRTEM) images show uniform hexagonal and layers structure of Zn-Fe LDH and confirms the polycrystalline nature as shown in Fig. 3(e). The Fig. 3g showed the layered feature of the prepared LDH with interplanar spacing $~ 0.25 \mathrm{~nm}$ which probably match with the FESEM [30]. 


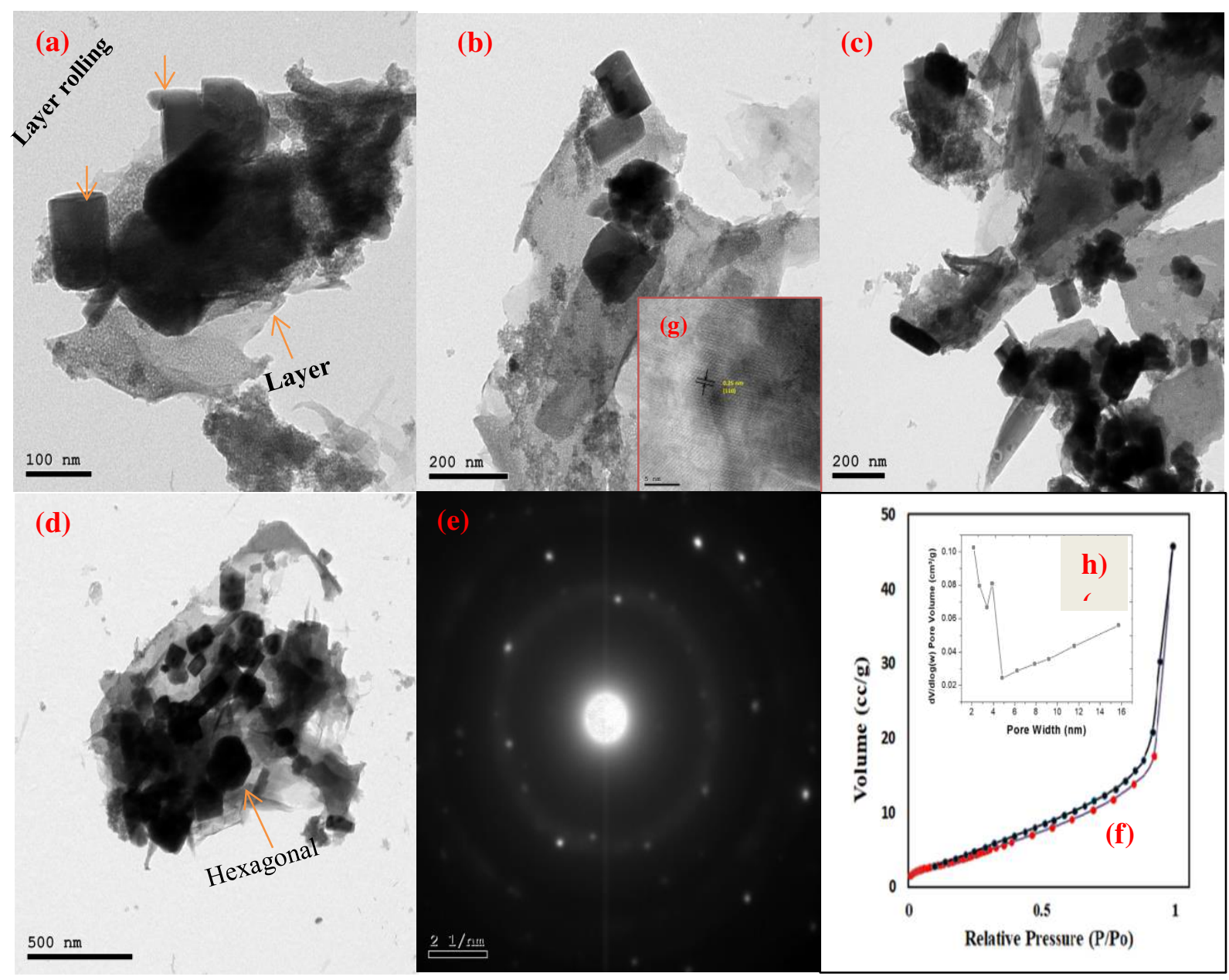

Fig. 3. HRTEM images of the (a-d); inset figure represent interplanar spacing (g); (SAED) The Selected Area Electron Diffraction (e) $\mathrm{N}_{2}$ adsorption-desorption isotherms (f) and inset Figure (h) for pore volume distribution for the prepared $\mathrm{Zn}-\mathrm{Fe} \mathrm{LDH}$.

\subsection{Surface property}

As shown in Fig. 3f, $\mathrm{N}_{2}$ adsorption/desorption isotherms of synthesized LDH we find the existence of small closed loop at relative pressure $>0.8$, and the absence of a plateau at the $\mathrm{P} / \mathrm{P}_{\mathrm{o}}$ near to 1 are followed to type II isotherm that is matches with $\mathrm{H}_{3}$-type hysteresis loop and that related to the mesopores/macroporous construction and capillary condensation process. The prepared sample has surface properties that estimated by (BET) method. BET surface area, the total pore volume and average pore size and of the sample are $71.61 \mathrm{~m}^{2} / \mathrm{g}, 0.078 \mathrm{~cm}^{3} / \mathrm{g}$ and 2.61 $\mathrm{nm}$, respectively. The average pore size is $<50 \mathrm{~nm}$ and there is extensive spreading of pore size up to16 nm (Fig.3h). (XPS) was applied for analysis the composition of LDH and assure the bonding of containing atoms. As observed from (Fig. 4) the XPS spectrum proved the existence 
of $\mathrm{Fe}, \mathrm{O}$ and $\mathrm{Zn}$. The $\mathrm{Zn} 2 \mathrm{p}$ spectra of XPS displayed two peaks asymmetric assigned to $\mathrm{Zn} 2 \mathrm{p}$ $3 / 2$ and $\mathrm{Zn} 2 \mathrm{p} 1 / 2$ core levels at 1021.8 and $1044.7 \mathrm{eV}$ respectively, which related to that $\mathrm{Zn}$ charge were in 2+ oxidation state in LDH [14]. The O 1s peak as showed in Fig 4 of pure material (LDH) was at $531.80 \mathrm{eV}$ which due to the presence of the -OH group of $\mathrm{Zn}-\mathrm{Fe} \mathrm{LDH}$ [31]. Moreover, the signal of $\mathrm{Fe} 2 \mathrm{p}$ of $\mathrm{Fe}^{3+}$ peaks intricate by $\mathrm{Fe} 2 \mathrm{p} 3 / 2(711.7 \mathrm{eV})$ and $\mathrm{Fe} 2 \mathrm{p} 1 / 2$ $(725.5 \mathrm{eV})$ refer to small positive change [32].
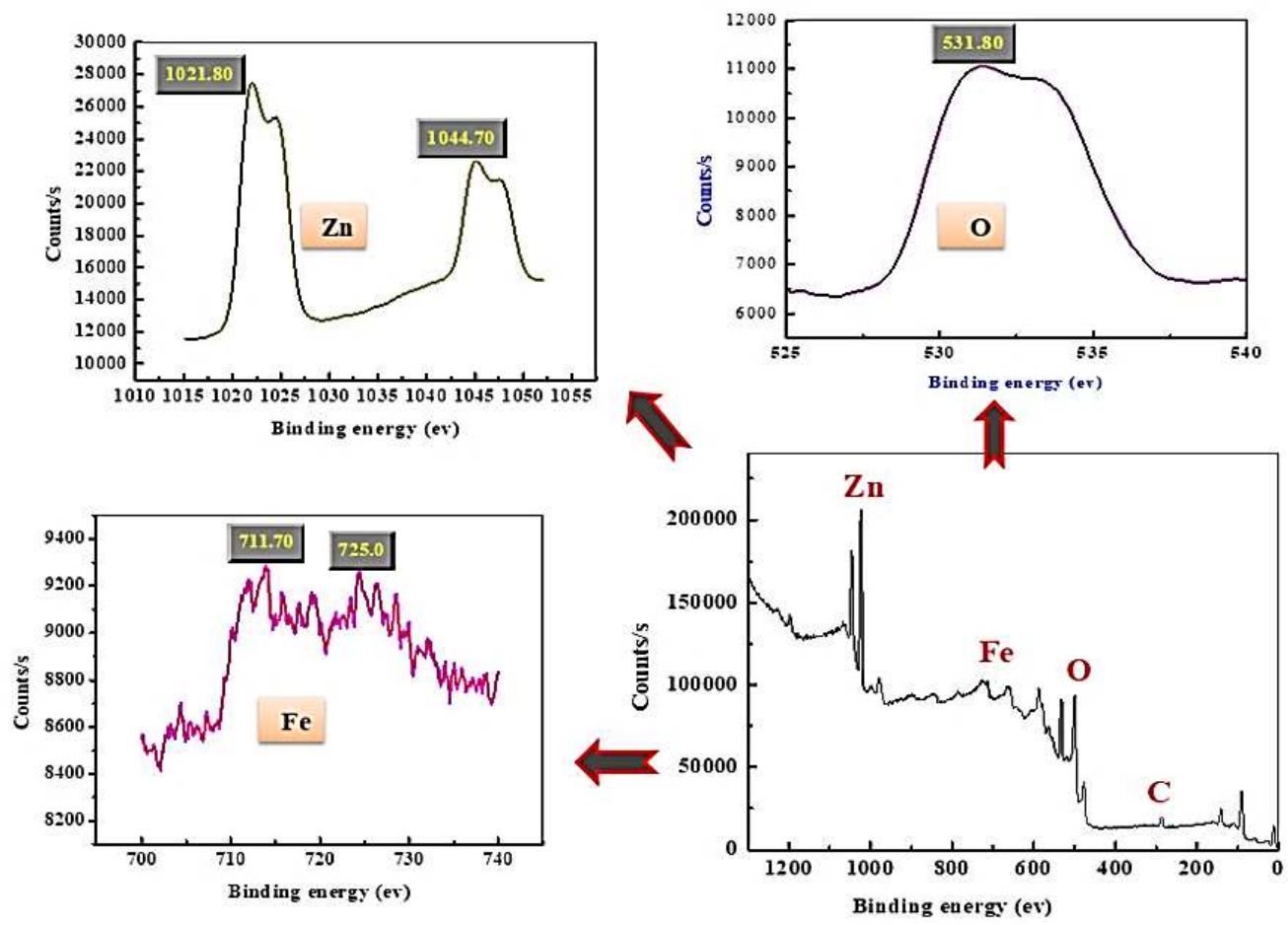

Fig. 4. X-ray photoelectron spectroscopy spectra of the prepared Zn-Fe LDH.

\subsection{Fourier transform-infrared of Zn-Fe LDH}



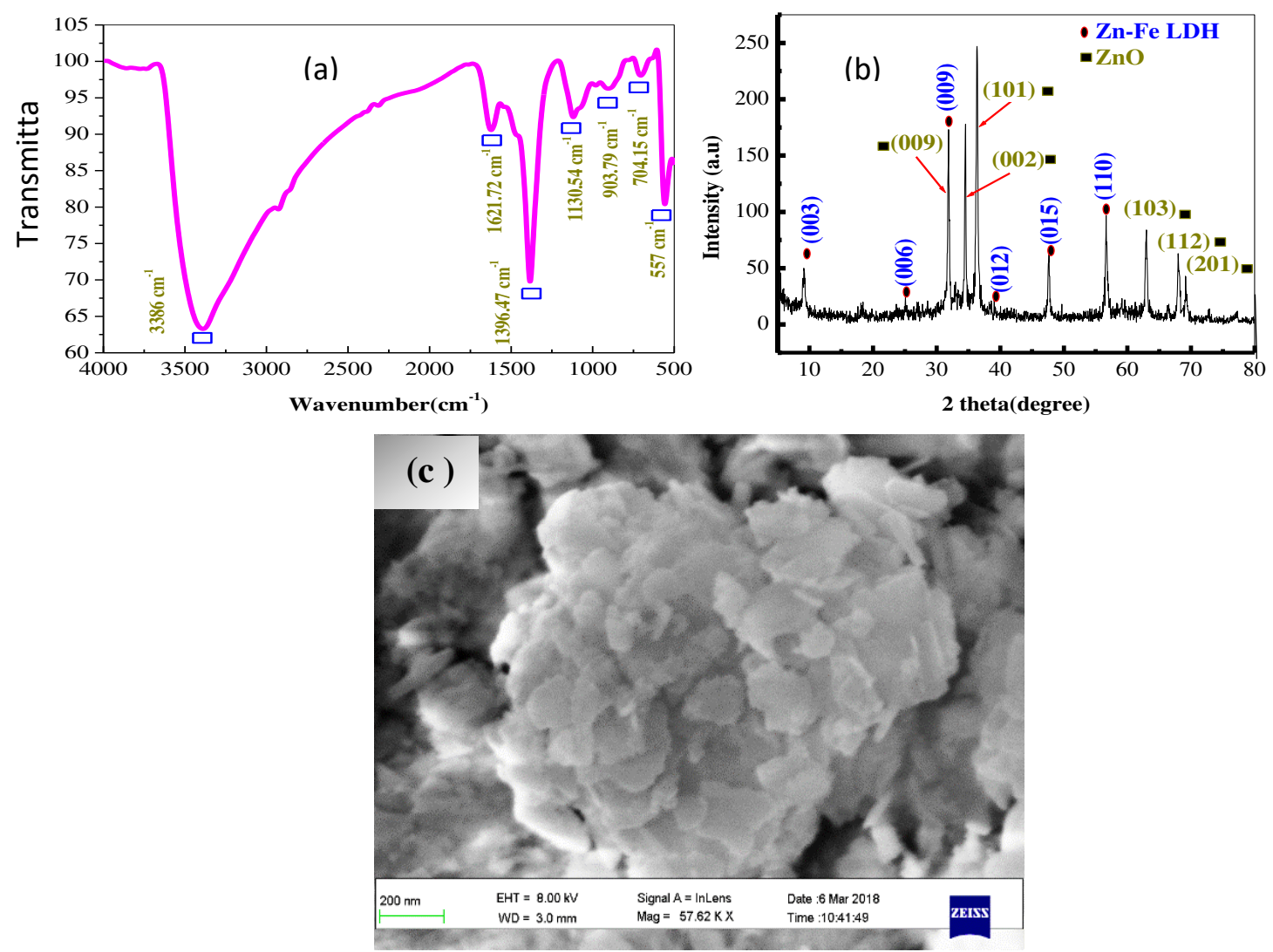

Fig. 5. (a) The FT-IR spectra, (b) XRD patterns, and (c) FESEM of the prepared Zn-Fe LDH.

\section{$3.4 X$-ray diffraction investigation}

The spectra of FTIR for Zn-Fe nitrate LDH was presented in Fig. 5a. The infrared peaks were around $3386 \mathrm{~cm}^{-1}$ which could be ascribed to characteristic free $\mathrm{OH}$-stretching of the LDH structure vibration[33] with the interlayer water molecules and hydrogen bonding [34, 35] and at $1621.72 \mathrm{~cm}^{-1}$, the band exhibited the bending vibration of the interlayer $\mathrm{H}_{2} \mathrm{O}$ water molecules. The peak situated at $1396.47 \mathrm{~cm}^{-1}$ was specified to the $v_{3}$ stretching vibration of the nitrate groups in the interlayer of LDH. below $1000 \mathrm{~cm}^{-1}$ the peaks resulted from $\mathrm{O}-\mathrm{M}-\mathrm{O}, \mathrm{M}-\mathrm{O}, \mathrm{M}-\mathrm{O}-$ $M$ vibrations in the clay-like layers [36, 37]. The bands showed around $903 \mathrm{~cm}^{-1}$ could be related to the anti-symmetric deformation mode $\left(v_{4}\right)$ of nitrate, and the weak out of plane symmetric deformation type $\left(v_{2}\right)[38]$.

The XRD analysis of Zn-Fe LDH showed a crystalline layered phase (Fig. 5b). The value of basal spacing $d$ of the $\mathrm{Zn}-\mathrm{Fe} \mathrm{LDH}$ was $(0.414 \mathrm{~nm})$. The value of $\mathrm{d}$ spacing was in good agreement with that of the LDH/nitrate type with reference code (04-018-3495). The presence of the main peaks of index (003), (006), (009), (012) and (018) confirmed the formation of layered 
structure of the Zn-Fe LDH. It could be observed that the bands were thin, proving that the exchange of $\mathrm{Fe}$ and $\mathrm{Zn}$ into the $\mathrm{Zn}-\mathrm{Fe} \mathrm{LDH}$ crystalline structure were achieved [39]. Since the peaks of (015) and (009) are higher intense than that for (003) which related to the creation of partly delaminated $\mathrm{Zn}-\mathrm{Fe} \mathrm{LDH}$ is probable this coincides with the innovative morphology through SEM images[35] (Fig. 5c). The diffraction peaks 31.60॰ 34.69॰, 36.48॰, 62.84॰, 67.90॰, and $69.44^{\circ}$ had been indicated and indexed as hexagonal phase of Zinc oxide.

\subsection{Optical properties}

The optical or photon properties of Zn-Fe LDH samples, such as the band gap energy, were identified using UV-Vis (NIR spectroscopy, DRS), and the resulting spectrum is displayed in Fig. 6, which describes the diffuse reflectance spectra of the samples. The average reflectance of the samples can be quantitatively expressed as an integral of the wavelength diffuse reflectance spectrum at the limits of $200-800 \mathrm{~nm}$. The $\left(h v F\left(R_{\infty}\right)\right)^{2}$ was drawn against the $h v$ using the Kubelka-Munk function, and the direct band gap of $\mathrm{Zn}-\mathrm{Fe}$ LDH nanoparticles could be evaluated by extrapolating the linear part of the curve as shown in Fig. 7a. We observed that the linear part of the graph confirms the direct band gap-type behavior of $\mathrm{Zn}-\mathrm{Fe} \mathrm{LDH}$ nanoparticles, and the approximate direct optical energy band gap is $3.25 \mathrm{eV}$.

The observed absorption coefficient value $\left(\alpha<10^{4} \mathrm{~cm}^{-1}\right)$ is representative of the indirect band gap for $\mathrm{Zn}-\mathrm{Fe} \mathrm{LDH}$ as a function of photon energy $(h v)$. We plot $(\alpha h v)^{1 / 2}$ and extrapolate the linear portion of curves to the values of $(\alpha h v)^{1 / 2}=0$. The intercepts in Fig. $7 \mathrm{~b}$ give the value of the indirectly allowed band gap energy $\left(E_{g}=1.76 \mathrm{eV}\right)$.

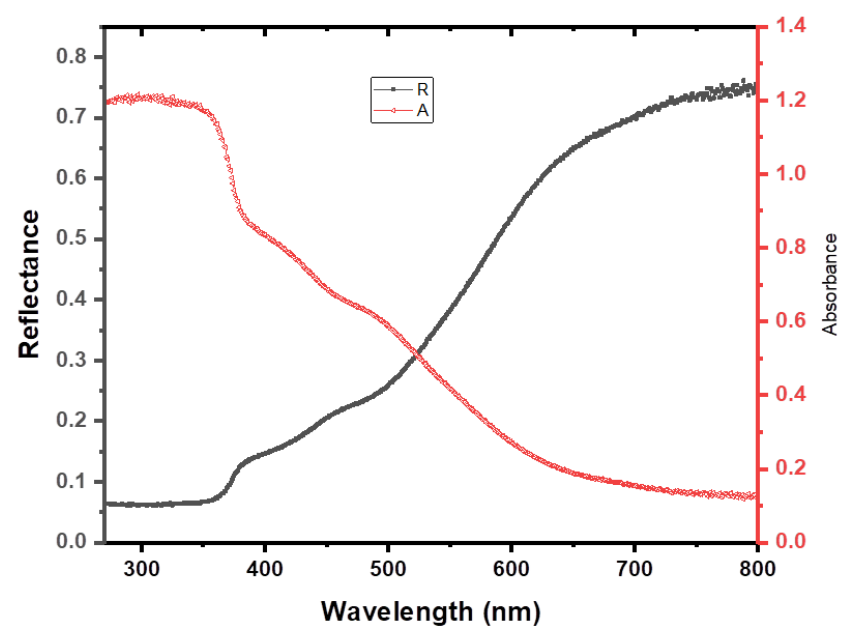

Fig. 6. UV-vis reflectance and absorbance of Zn-Fe LDH 

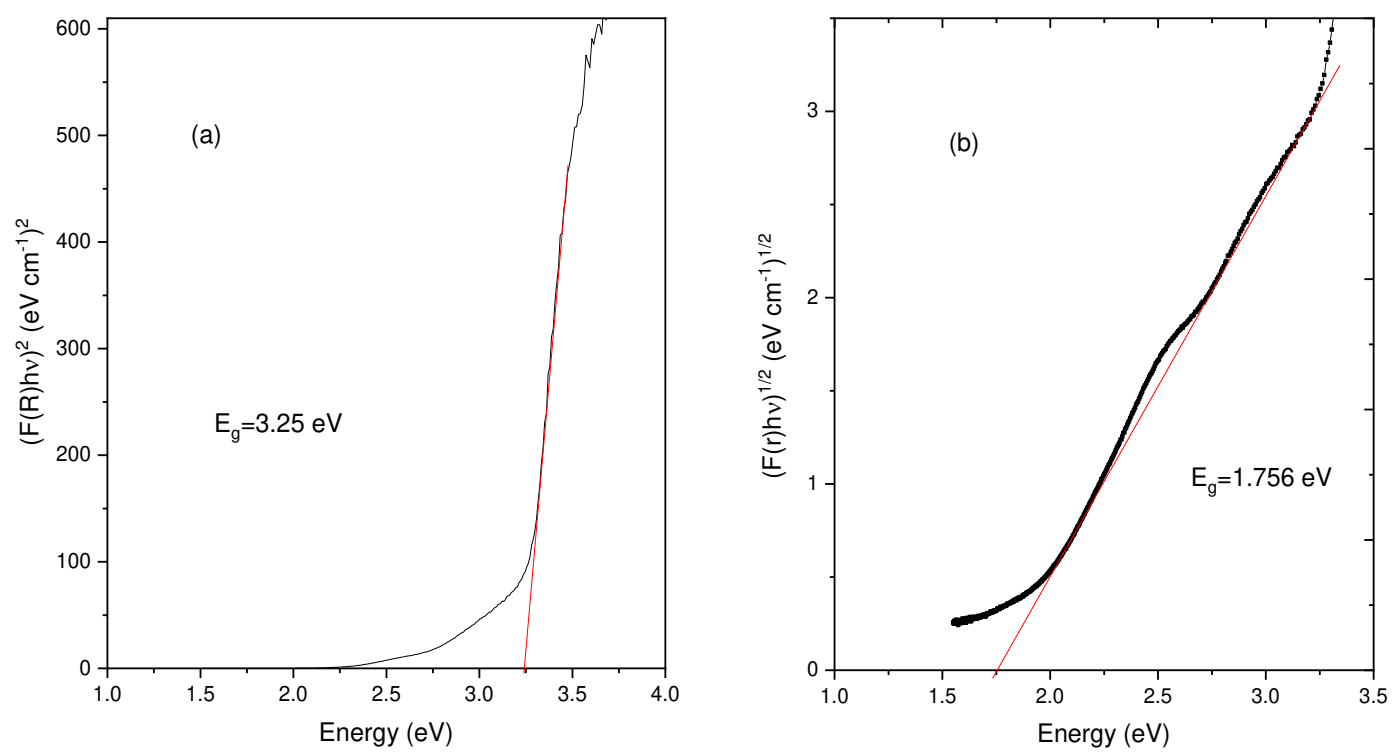

Fig 7. Tauc plot showing a possible fit to obtain the bandgap for $\mathrm{Zn}-\mathrm{Fe}$ LDH with (a) direct and (b) indirect transitions.

The theory of reflectivity of light has been used to calculate the values of other optical parameters like $k$ and $n$. The values of $k$ and $n$ have been calculated using the following equations [4-6]:

$k=\alpha \lambda / 4 \pi$

and $n=(1+R)+\left[(1+R)^{2}-(1-R)^{2}\left(1+k^{2}\right)\right]^{1 / 2} /(1-R)$.
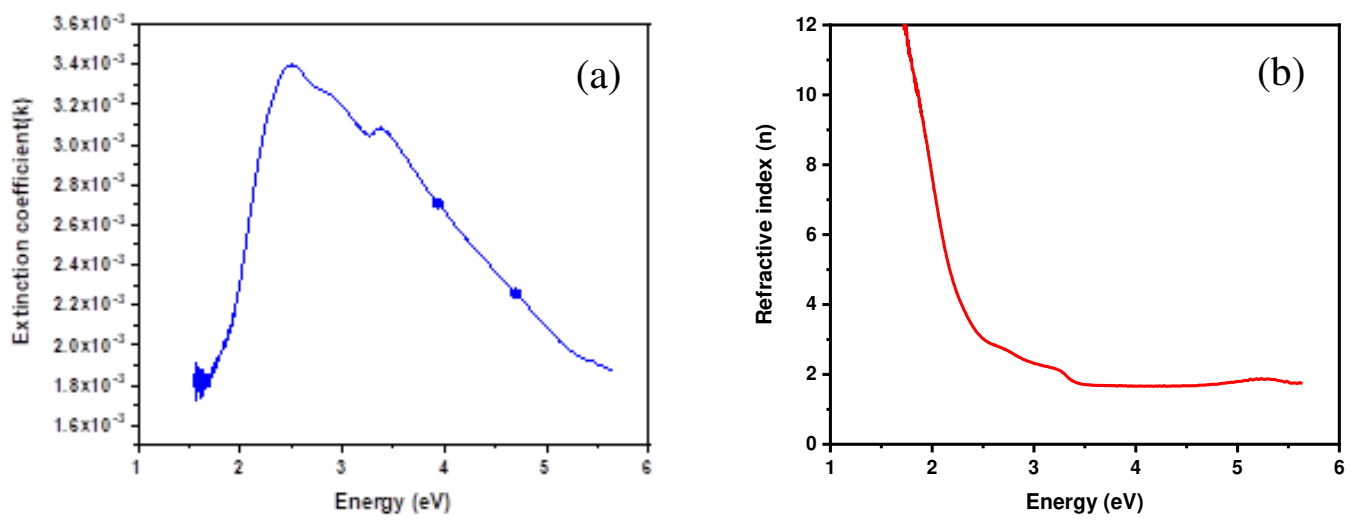

Fig 8. (a) Variations in the extinction coefficient $(k)$ and (b) variations in the refractive index $(n)$ as a function of energy for $\mathrm{Zn}-\mathrm{Fe} \mathrm{LDH}$.

The variances of the refractive index and the coefficient of extinction with energy are shown in Figs. 8(a-b), respectively. The extinction coefficient is an indicator of the amount of energy lost in the substance owing to the dispersion or absorption caused by molecules and 
particles. The extinction coefficient is high in the $200-360 \mathrm{~nm}$ wavelength range and low in the 360-800 $\mathrm{nm}$ wavelength range. The changes in the coefficient of extinction are related directly to the absorption of light, whereas the value of the refractive index decreases sharply with an increase in the photon energy in the visible region up to $\lambda=500 \mathrm{~nm}$; it is almost constant in the 500-800 $\mathrm{nm}$ region. For the additional investigation of the optical data, several useful relationships can be inferred to link the real and imaginary parts of the dielectric function and the optical constants ( $n$ and $k$ ). The accompanying relationships have been utilized to compute the values of the real part $\left(\varepsilon_{r}\right)$ and imaginary part $\left(\varepsilon_{i}\right)$ of the dielectric constant for Zn-Fe LDH [4]

$$
\varepsilon_{r}=n^{2}-\kappa^{2} \quad \text { and } \quad \varepsilon_{i}=2 n \kappa .
$$

Its variety with photon energy is depicted in Fig. 9. From Fig. 9, we can see that the dielectric loss and dielectric constant diminish with photon energy analogs according to the behavior reported in the literature [40]. The magnitudes of the real dielectric constant are higher than the imaginary dielectric constant since they are reliant on $n$ and $k$ values. The real part of the dielectric constant contains a term that describes the amount by which it will impede the speed of light in the material, and the imaginary part shows how a dielectric absorbs energy from an electric field because of dipole movements [41].

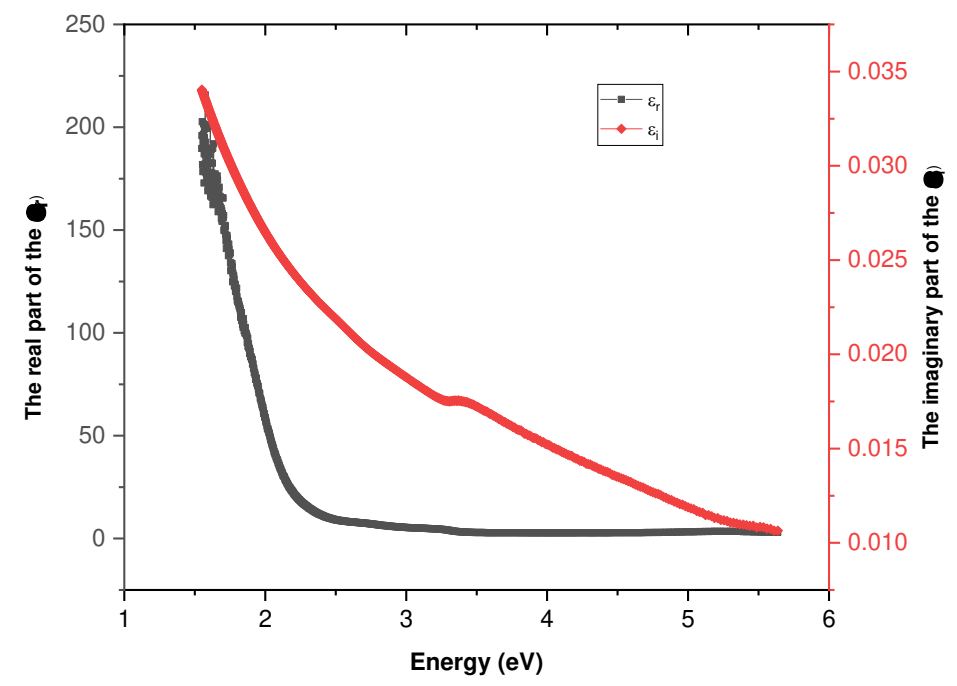

Fig. 9. Variation of real and imaginary parts of the dielectric constant with incident photon energy $(h v)$.

The optical conductivity, which is related to the refractive index and absorption coefficient as given below, is then determined: 


$$
\sigma_{o p t}=n c \alpha / 4 \pi
$$

where $c$ is the speed of light in a vacuum. The reliance of the optical conductivity on the incident photon energy for various $\mathrm{Zn}-\mathrm{Fe} \mathrm{LDH}$ nanoparticles is displayed in Fig. 10. It can be observed that absorption is moderately low at high wavelengths, indicating a lower probability of electron transition to higher energy bands. On the contrary, at low wavelengths (i.e., at high energies), absorption is high, demonstrating greater opportunities for electron transitions.

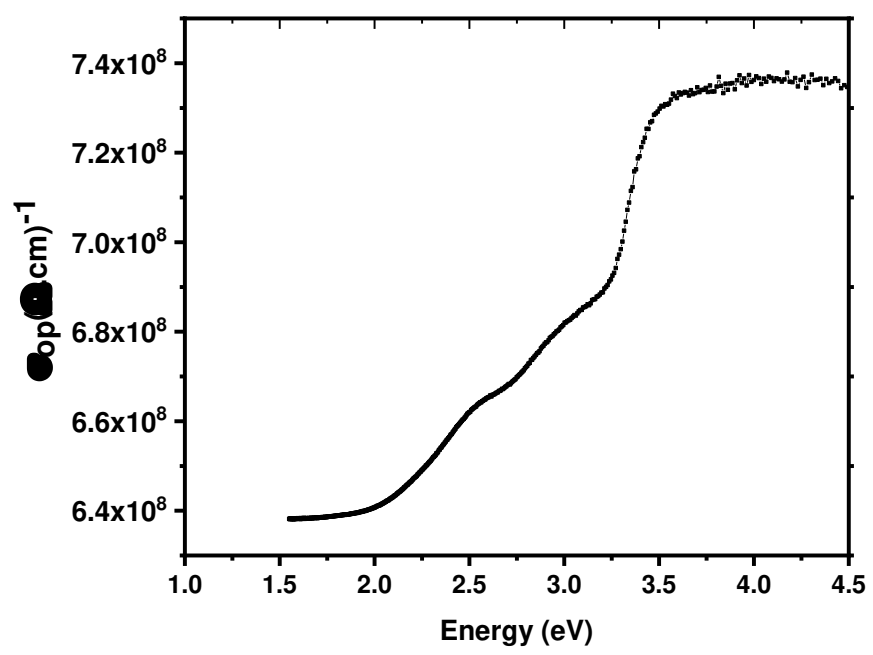

Fig. 10. Optical conductivity as a function of photon energy.

\subsection{Dielectric properties}

Fig. 11a outlines the change in the dielectric constant $\left(\varepsilon^{\prime}\right)$ for samples to the frequency at various temperatures. The dielectric constant $\varepsilon^{\prime}$ is a measure of the stored charge. The following clarification may be given regarding the nature of the dielectric permittivity for free oscillating dipoles in a varied field. When $\omega<<\tau^{-1}$, dipoles follow the field. Dipoles start to lag behind the field as the frequency increases (with $\omega<1 / \tau$ ), and $\varepsilon^{\prime}$ decreases slightly. The dielectric constant drops (relaxation process) when the frequency surpasses the characteristic frequency $(\omega=1 / \tau)$. Dipoles at this point do not comply with the field, and $\varepsilon^{\prime}=\varepsilon_{\infty}$ (high frequency values of $\varepsilon^{\prime}$ ) at extremely high frequencies $(\omega>>>1 / \tau)$. At low frequency, the dielectric constant is very high, and it is initially found to diminish with frequency and then to become somewhat stabilized. The high value of $\varepsilon^{\prime}$ at frequencies less than $1 \mathrm{kHz}$, which increases as the frequency diminishes and the temperature increases, corresponds to the system's bulk effect. The issue of interfacial charge carriers is an important factor for the improvement of dielectric values in the frequency region. 
The requirement for the high value of the dielectric constant in the low-frequency area can be obstructing the charge carriers at the electrode. At low frequency, the dielectric loss is extremely high, but with increasing frequency, it falls rapidly. The dielectric loss increases with increasing temperature, analogous to the temperature reliance of the dielectric constant as shown in Fig. 11b. At chosen frequencies, the dielectric loss value is found to increase as a function of temperature. This mechanism can be joined with the lagging behind of charged ion species with the applied energy that prompts polarization.
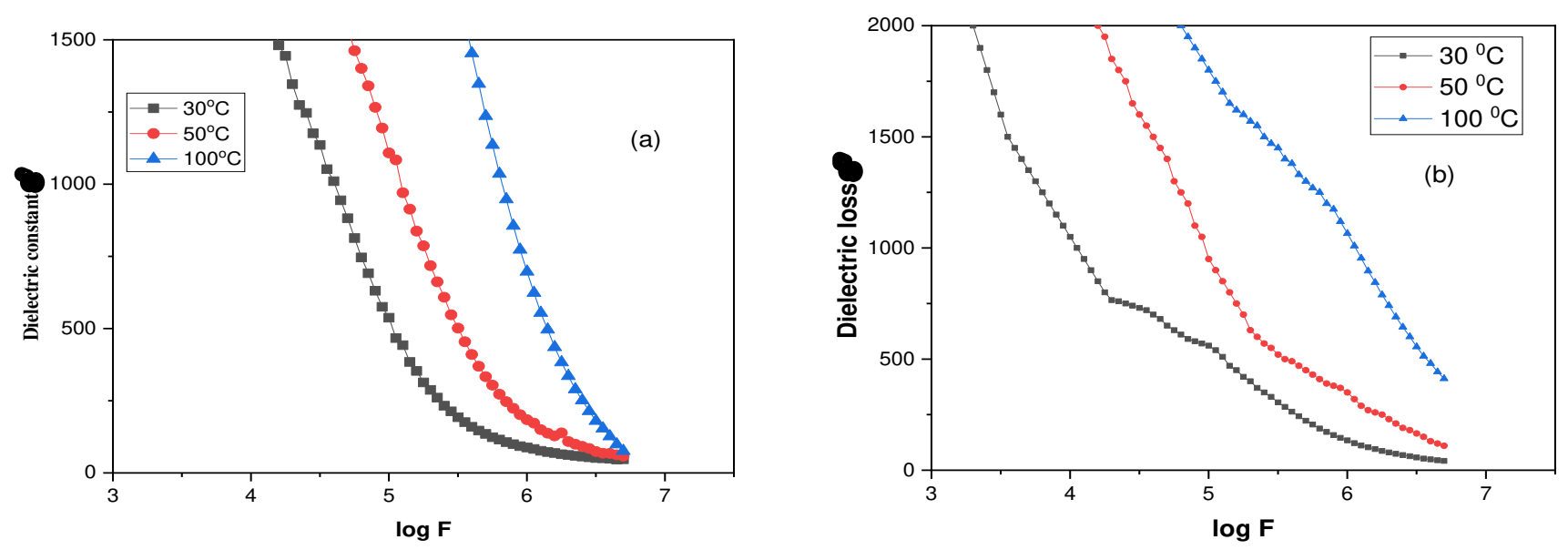

Fig. 11. (a) The dielectric constant and (b) the dielectric loss as a function of frequency at different temperatures.

\subsubsection{Conductivity}

Figure 12 shows the variety of AC electrical conductivity $\sigma_{\mathrm{ac}}$ of $\mathrm{Zn}-\mathrm{Fe} \mathrm{LDH}$ as a function of frequency at various temperatures. The conductivity plot has the accompanying characteristics: (i) scattering at lower and converging at higher frequencies of conductivity spectra with increased temperature. With increasing temperature, the plot shows that conductivity increments. In the low-frequency region, frequency independent conductivity behavior is noticed, but that becomes sensitive in the high-frequency region, generally known as hopping frequency, moved to the higher-frequency side with increment of temperature. The conductivity increments in the higher-frequency region, because of the hopping of charge carriers in finite clusters. 


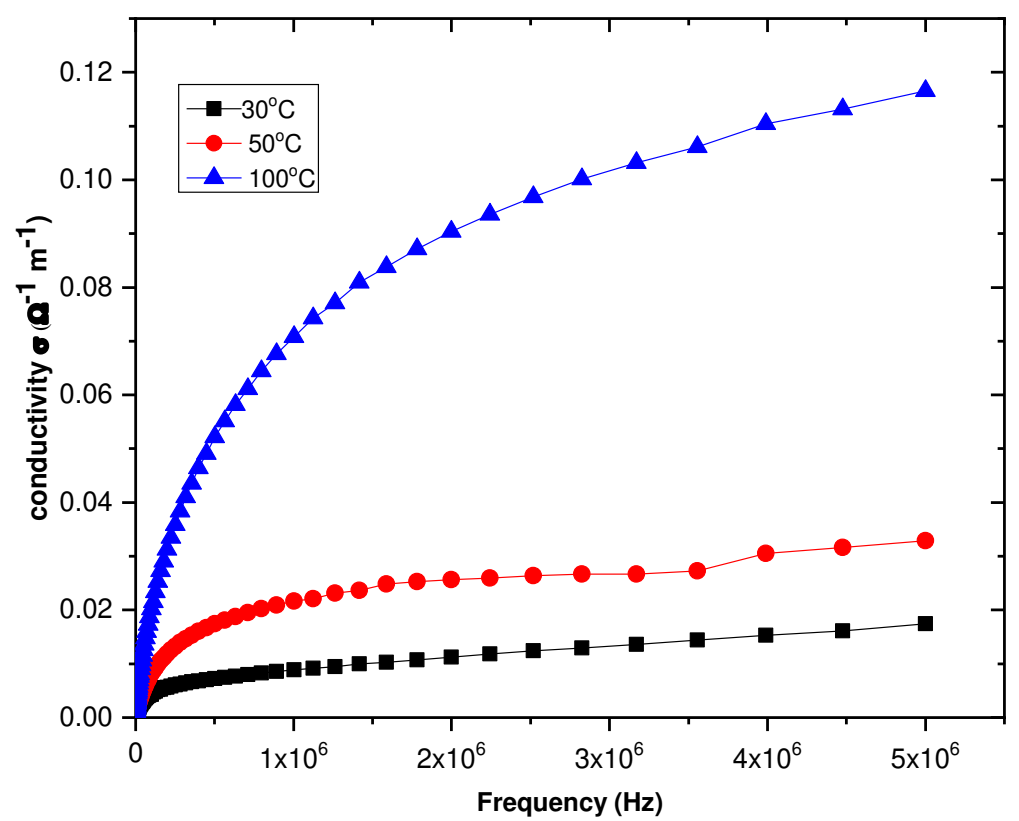

Fig. 12. Frequency dependence of AC conductivity of $\mathrm{Zn}-\mathrm{Fe} \mathrm{LDH}$ at different temperatures.

\subsection{Adsorption of dyes onto $\mathrm{Zn}-\mathrm{Fe} \mathrm{LDH}$}

The $\mathrm{pH}$ has a great effect on the adsorption process, where above a $\mathrm{pH}$ of $4, \mathrm{MO}$ develops a negative charge owing to its dissociation constant of 3.47 (Fig. 13a). At pH 7, it reaches the maximum adsorption value, and beyond this value, the adsorption decreases. In acidic media, MO was protonated at its nitrogen-nitrogen double bond, and so the adsorption percent decreased owing to the forces of electrostatic repulsion. Reaching equilibrium in alkaline media was difficult owing to a high quantity of $\mathrm{OH}^{-}$, which competes with anionic $\mathrm{MO}$ and thereby prevents adsorption equilibrium [42]. Zeta potential is a technique to study the stability of the prepared material and dispersion in solution (Fig. 13b). The high stability of the Zn-Fe LDH nanoparticle dispersions is related to the high positive zeta potential over a large $\mathrm{pH}$ range (210), leading to strong particle-particle repulsions. Moreover, in considering the surface charge and surface properties for the adsorption behavior of prepared LDH with different dyes, the positive zeta potential of $\mathrm{LDH}$ is consistent with the electrostatic attraction between $\mathrm{MO}$ and LDH and supports the process of adsorption. By increasing the $\mathrm{pH}$, the positive surface charge of the adsorbent decreases, thus leading to a decrease in the attraction of the negatively charged MO species, which increases the adsorption of anionic dyes (Fig. 13a). In the acidic medium, the surface of the $\mathrm{Zn}-\mathrm{Fe} \mathrm{LDH}$ has a positive charge, and the MG and MB exist as cationic species (with a positive charge) [22]. Therefore, at low $\mathrm{pH}$, adsorption is decreased owing to electrostatic 
repulsion (Figs. 13(c-d)). The MG and MB removal sharply increased to $81 \%$ and $84 \%$, respectively, at a $\mathrm{pH}$ of 6 for $\mathrm{MG}$ and 9 for $\mathrm{MB}$. At a $\mathrm{pH}$ higher than 6-8, the adsorption of MG likely increases owing to $\mathrm{OH}^{-}$groups that are attracted to the positive molecules of MG. It was reported that the PZC value of $\mathrm{Zn}-\mathrm{Fe} \mathrm{LDH}$ is 6.72 (Fig. 13e) [22], which is consistent with electrostatic attraction either between MG molecules or between $\mathrm{MB}$ and $\mathrm{Zn}-\mathrm{Fe} \mathrm{LDH}$. To demonstrate the stability of the partial in several media, we estimate the practical size distribution (DLS) measurements. As observed in Fig. 13f, using Zn-Fe LDH with a smaller hydrodynamic size led to better aquatic stability and higher zeta potential. Moreover, this could allow its long-term application as a potential adsorbent for different pollutants in aquatic systems. Furthermore, to prove the stability of the adsorbent in low $\mathrm{pH}$, we investigate the XRD spectrum of LDH in acidic media (Fig. 13g). The results showed that the material was maintained at characteristic peaks of LDH [43], as presented in Fig. 13g. 

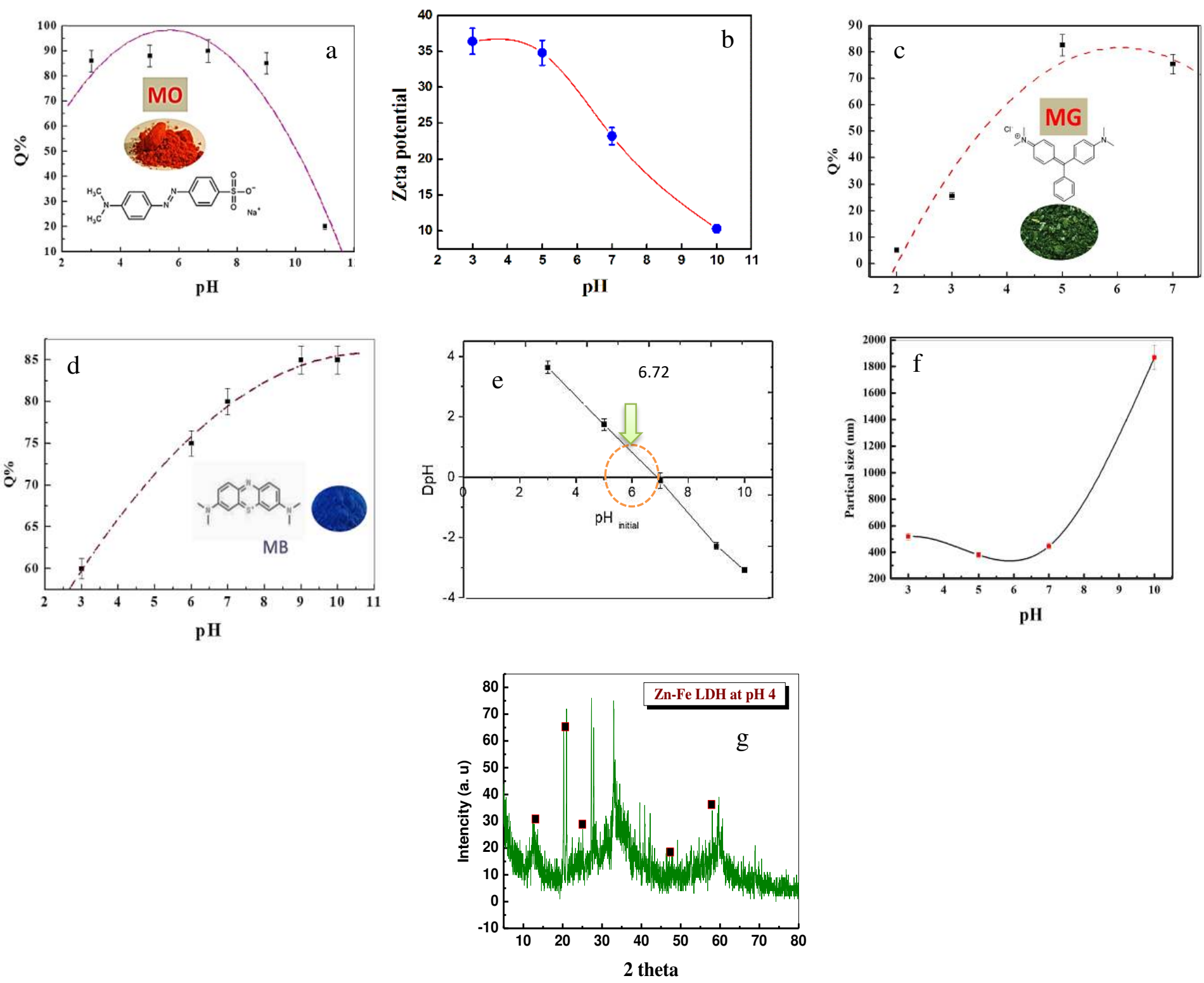

Fig. 13. Percent removal of different dyes (a,c,d); (b) zeta potential; (e) PZC; (f) partial size distribution of $\mathrm{Zn}-\mathrm{Fe} \mathrm{LDH}$ at different $\mathrm{pH}$ values; and (g) XRD spectra of $\mathrm{Zn}-\mathrm{Fe} \mathrm{LDH}$ at $\mathrm{pH} 4$.

\subsubsection{Adsorption isotherm studies}

Adsorption isotherms explain how molecules of the adsorbate are distributed between the solid and liquid phases as the adsorption process reaches an equilibrium state. Modeling is crucial to compare and predict the LDH for which two- or three-parameter isotherm models apply well. Two-parameter models are commonly applied owing to simplicity and ease of fitting, and because the two-parameter 
models fit the data well, the use of a more complex model is not required. The adsorption isotherms for MB, MO, and MG are shown in Fig. 14.
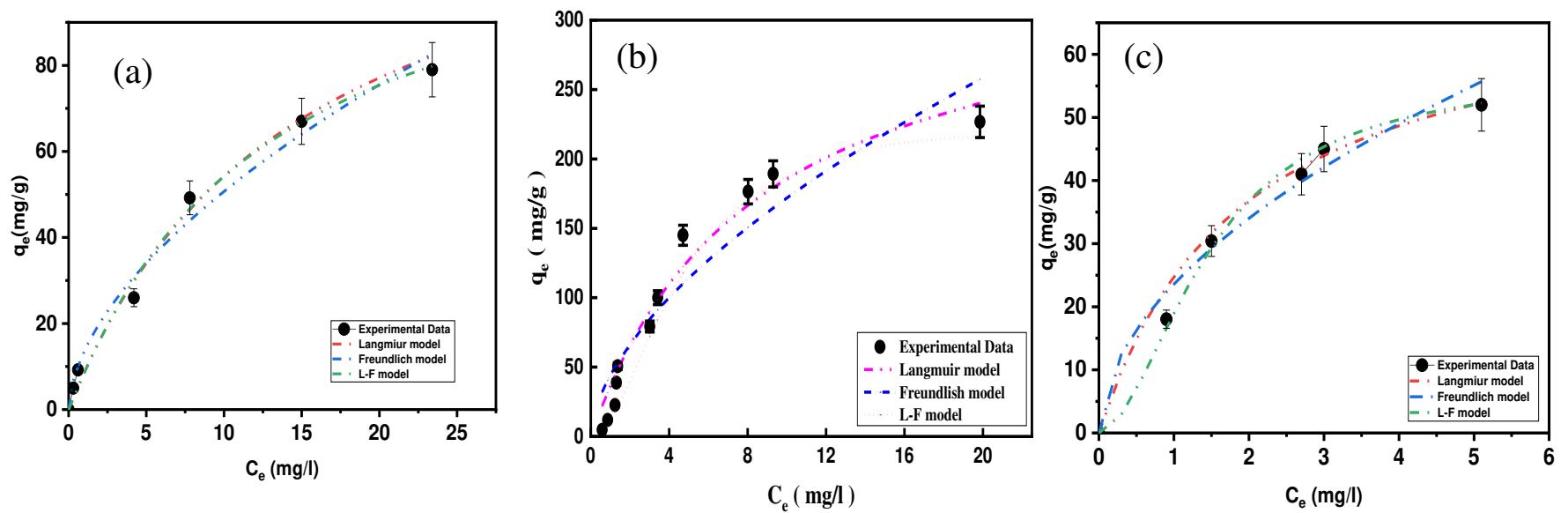

Fig. 14. Experimental adsorption isotherm data of (a) MB, (b) MO, and (c) MG dye on LDH fitted using two- and three-parameter isotherms.

Isotherm models explain the behavior of the adsorption of $\mathrm{MB}, \mathrm{MO}$, and $\mathrm{MG}$ well upon comparing the calculated values from adsorption isotherms with experimental values applied to fit the experimental data using a nonlinear relationship with a Langmuir adsorption isotherm model [44]. The Langmuir adsorption isotherm is widely used for the modeling of homogeneous adsorption on the surface of the monolayer and assumes that the adsorbent surface is uniform and that all sorption sites are identical. The Freundlich isotherm model is suitable for heterogeneous adsorbent surfaces and multilayer adsorption. The Langmuir-Freundlich (L-F) isotherm model is used for both heterogeneous and homogeneous distributions at high and low concentrations [45]. Also known as the Sips equation, it is a function that describes heterogeneous systems. Tables 2 and 3 indicate that all isotherm models predict the adsorption behavior of $\mathrm{MB}, \mathrm{MO}$, and MG well based on the statistical analysis of the correlation coefficient $\mathrm{R}^{2}$; for $\mathrm{MB}, \mathrm{R}^{2}$ was 0.996 and 0.993 for the Langmuir and Langmuir-Freundlich isotherm models, respectively, whereas the $q_{e}$ was $133.29 \mathrm{mg} / \mathrm{g}$. Based upon this result, the Langmuir model was the best model for explaining the adsorption process, where homogeneous adsorption is on the surface of the monolayer, and the surface of $\mathrm{LDH}$ is uniform and without interactions between adsorbents. This indicates that the Langmuir model is more suitable for explaining the process of MB adsorption and better represents the experimental data. The $\mathrm{R}^{2}$ for $\mathrm{MO}$ was 0.990 for the Langmuir-Freundlich model isotherm, and the following order for $\mathrm{R}^{2}$ was observed: Langmuir-Freundlich>Langmuir $>$ Freundlich. The maximum adsorptivity $\left(q_{e}\right)$ was 230.68 , and 
these results indicate that multilayer adsorption occurred on heterogeneous surfaces. The Langmuir-Freundlich model was more suitable to describe and explain the process of the adsorption of MO with $\mathrm{Zn}-\mathrm{Fe} \mathrm{LDH}$. For MG, the correlation coefficient was 0.997 for the Langmuir-Freundlich model isotherm. This suggests that the Langmuir-Freundlich model was better than other applied models due to the presence of chemical bonds between metal ions $(\mathrm{LDH})$ and dye, with ion exchange in solution. (Langmuir-Freundlich>Freundlich>Langmuir; $q_{e}$ of $57.34 \mathrm{mg} / \mathrm{g}$.) The mechanism of adsorption can be investigated using FT-IR spectra. The FTIR spectrum of the $\mathrm{Zn}-\mathrm{Fe} \mathrm{LDH}$, after the addition of MG, showed peaks in the $800-400 \mathrm{~cm}^{-1}$ fingerprint wavenumber region. These peaks are consistent with the paradisubstituted and monosubstituted benzene rings present in MG and confirm its adsorption onto the LDH surface (Fig. 15). This was further supported by the characteristic peak at $1585 \mathrm{~cm}^{-1}$ related to the $\mathrm{C}=\mathrm{C}$ of the benzene ring as well as the peak at $1373.5 \mathrm{~cm}^{-1}$ owing to- $\mathrm{CH}_{3}$. The adsorption of MO or MB on Zn-Fe LDH was confirmed through FT-IR analysis (Fig. 15). We observe a small intense peak at $1618 \mathrm{~cm}^{-1}$ consistent with the $\mathrm{C}-\mathrm{C}$ vibration band of the benzene ring related to the MO chemical structure. The peaks at 1138 and $1370 \mathrm{~cm}^{-1}$ were related to stretching vibrations of C$\mathrm{C}$ and $\mathrm{C}-\mathrm{N}$, respectively. $\mathrm{C}-\mathrm{H}$ stretching vibration peaks of the benzene ring were located at 1030 and $837 \mathrm{~cm}^{-1}$, whereas the peaks present at $629.5 \mathrm{~cm}^{-1}$ were assigned to the $\mathrm{C}-\mathrm{S}$ stretching vibrations.

Table 2. The adsorption isotherm and kinetics models

\begin{tabular}{llll}
\hline Isotherm models & Equations & Kinetics models & Equations \\
\hline Langmuir & $q_{e}=\frac{q_{\max } K_{L} C_{e}}{1+K_{L} C_{e}}$ & Pseudo-first-order & $q_{t}=q_{e}\left(1-e^{-k_{1} t}\right)$ \\
Freundlich & $q_{e}=K_{f} C_{e}^{1 / n_{F}}$ & Pseudo-second-order & $q_{t}=\frac{q_{e}^{2} k_{2} t}{1+q_{e} k_{t} t}$ \\
Langmuir-Freundlich & $q_{e}=\frac{q_{\max }\left(K_{L F} C_{e}\right)^{\beta_{L F}}}{1+\left(K_{L F} C_{e}\right)^{\beta_{L F}}}$ & Intraparticle & \\
& & diffusion & $q_{t}=k_{i p} \sqrt{t}+c_{i p}$ \\
& & Avrami & $q_{t}=q_{e}\left(1-e^{\left(-k_{a v} t\right)^{n_{a r}}}\right.$ \\
\hline
\end{tabular}

* The adjustable isotherm/kinetics model parameters are defined in the list of symbols 
Table 4 shows the comparison of $\mathrm{Zn}-\mathrm{Fe} \mathrm{LDH}$ with other adsorbents to further estimate the role of synthesis materials for the wastewater remediation of anionic dyes (MO) and cationic dyes (MB and MG). The maximum adsorption capacity ( $q_{\max }$, obtained from isotherm model fits) for this LDH is carefully compared with those for other adsorbents. Considering the high adsorption capacity, it seems that the $\mathrm{Zn}-\mathrm{Fe}$ LDH prepared in this study could potentially be used as a cost-effective adsorbent for dye-polluted aquatic systems.

Table 3. Adsorption isotherm constants for the adsorption of MB, MO, and MG dyes in single systems.

\begin{tabular}{|c|c|c|c|c|}
\hline Isotherm models & $\begin{array}{l}\text { Adjustable model } \\
\text { parameters }\end{array}$ & Values & $R^{2}$ & $\chi^{2}$ \\
\hline \multicolumn{5}{|l|}{ Methylene blue } \\
\hline \multirow[t]{2}{*}{ Langmuir } & $q_{\max }$ & 133.29 & 0.996 & 0.00035 \\
\hline & $K_{\mathrm{ad}}$ & 0.069 & & \\
\hline \multirow[t]{2}{*}{ Freundlich } & $K_{\mathrm{f}}$ & 13.48 & 0.980 & 0.00120 \\
\hline & $1 / n_{\mathrm{F}}$ & 0.575 & & \\
\hline \multirow[t]{3}{*}{ Langmuir-Freundlich } & $q_{\max }$ & 119.51 & 0.993 & 0.00038 \\
\hline & $K_{\mathrm{LF}}$ & 0.0836 & & \\
\hline & $\beta_{L F}$ & 1.04 & & \\
\hline \multicolumn{5}{|l|}{ Methyl orange } \\
\hline \multirow[t]{2}{*}{ Langmuir } & $q_{\max }$ & 133.29 & 0.996 & 0.00035 \\
\hline & $K_{\mathrm{ad}}$ & 0.069 & & \\
\hline \multirow[t]{2}{*}{ Freundlich } & $K_{\mathrm{f}}$ & 13.48 & 0.980 & 0.00120 \\
\hline & $1 / n_{\mathrm{F}}$ & 0.575 & & \\
\hline \multirow[t]{3}{*}{ Langmuir-Freundlich } & $q_{\max }$ & 230.68 & 0.990 & 0.000629 \\
\hline & $K_{\mathrm{LF}}$ & 0.220 & & \\
\hline & $\beta_{L F}$ & 1.86 & & \\
\hline \multicolumn{5}{|l|}{ Malachite Green } \\
\hline \multirow[t]{2}{*}{ Langmuir } & $q_{\max }$ & 71.74 & 0.969 & 0.00029 \\
\hline & $K_{\mathrm{ad}}$ & 0.527 & & \\
\hline Freundlich & $K_{\mathrm{f}}$ & 23.63 & 0.917 & 0.00180 \\
\hline
\end{tabular}




\begin{tabular}{lllll}
\hline & $1 / n_{\mathrm{F}}$ & 0.526 & & \\
Langmuir-Freundlich & $q_{\max }$ & 57.34 & 0.997 & 0.000052 \\
& $K_{\mathrm{LF}}$ & 0.685 & & \\
& $\beta_{L F}$ & 1.854 & & \\
\hline
\end{tabular}
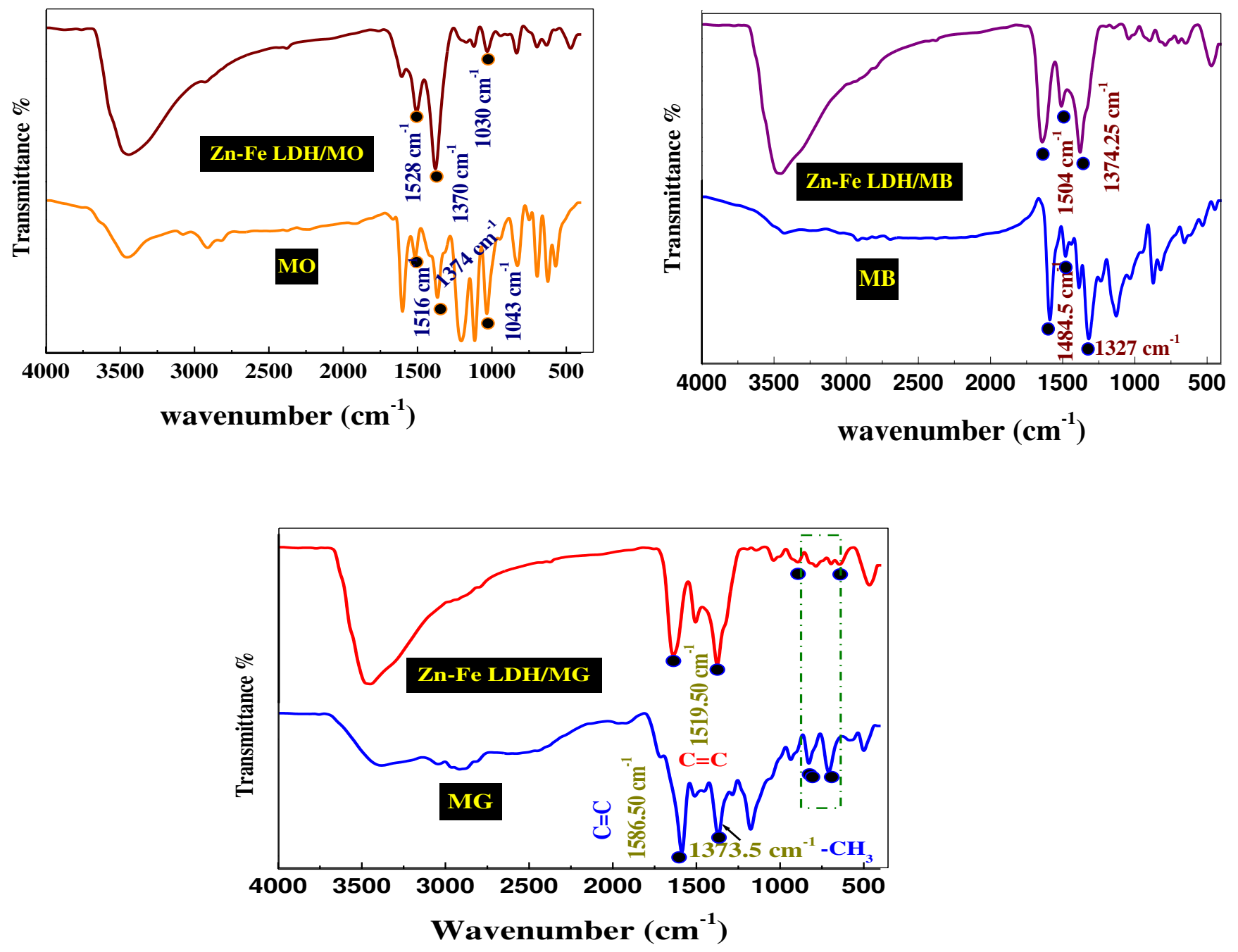

Fig. 15. The FT-IR spectra of Zn-Fe LDH samples before and after adsorption of MG, MB, and MO dyes. 
Table 4. Comparison of the maximum adsorption capacities for the removal of MG using different LDHs as adsorbents.

\begin{tabular}{llll}
\hline Adsorbents & $q_{\max }(\mathrm{mg} / \mathrm{g})$ & $\mathrm{C}$ initial $(\mathrm{mg} / 1)$ & dye/References \\
\hline $\mathrm{NiFe}-\mathrm{LDH}$ & 205.76 & $20-200$ & $\mathrm{MO} /[46]$ \\
$\mathrm{Ni} / \mathrm{Al} \mathrm{LDH}$ & 27.32 & 30 & $\mathrm{MG} /[47]$ \\
$\mathrm{Cu} / \mathrm{Cr}-\mathrm{LDH}$ & 55.86 & 50 & $\mathrm{MG} /[48]$ \\
$\mathrm{MMT} @ \mathrm{NiFe} \mathrm{LDH}$ & 99.18 & 30 & $\mathrm{MB} /[49]$ \\
$\mathrm{Fe} / \mathrm{SCD}-\mathrm{LDH}$ & 83.44 & 100 & $\mathrm{MB} /[50]$ \\
$\mathrm{Mg} 3 \mathrm{Al} \mathrm{LDH}$ & 46.72 & 0.75 & $\mathrm{MB} /[51]$ \\
\hline
\end{tabular}

\subsubsection{Ternary adsorption isotherm studies}

As shown in Fig. 16, the adsorption capacity $\left(q_{e}\right)$ of dyes is negatively affected when the concentration of each dye in the mixture is increased in the range of $10-1000 \mathrm{mg} / \mathrm{L}$. The decrease in the adsorption capacity of $\mathrm{MB}$ and $\mathrm{MG}$ is lower than $\mathrm{MO}$, which is probably due to the affinity of MO toward the positively charge adsorbent surface (Table 5). On the other hand, MG and MB show the opposite behavior from that shown by MO since $\mathrm{Zn}-\mathrm{Fe}$ LDH presents a high affinity toward anionic dyes (Fig. S1). We can conclude that interactions are being favored basically for the removal of anionic dyes like MO rather than cationic, as is the case for MB or MG. Langmuir, Freundlich, and Langmuir-Freundlich adsorption isotherms are applied to study the adsorption capacity exhibited by LDH used and the concentration of dyes at equilibrium. The Langmuir adsorption isotherm assumes homogeneous monolayer adsorption, whereas the Freundlich isotherm assumes heterogeneous multilayer adsorption. The adsorption isotherms assist in investigating the maximum adsorption capacity and the adsorption mechanism (Table 5). As shown from the calculated parameters (Table 5) and the isotherm plots for dye adsorption (Fig. 16), the Langmuir-Freundlich isotherm model better explains dye adsorption on LDH, indicating multilayer adsorption in the following order: $\mathrm{MO}>\mathrm{MB}>\mathrm{MG}$. $\mathrm{MB}$ and $\mathrm{MO}$ are flat and slightly hydrophobic molecules with rigid heterocyclic aromatic rings [52]. Hydrophobic interactions lead to a strong tendency of $\mathrm{MO}$ and $\mathrm{MB}$ to form dimers and trimers (the dimerization of MO and MB were 3.96 and 2.38, respectively [53]). These results in multilayers of MO formed on the surface of the adsorbent [30], which agrees with the adsorption results (Table 5) [40-43, 46]. [40-44]. 
Table 5. Langmuir, Freundlich, and Langmuir-Freundulich isotherm constants for the adsorption on of MB, MB, and MG dyes on LDH in the ternary system.

\begin{tabular}{|c|c|c|c|c|}
\hline Isotherm models & $\begin{array}{l}\text { Adjustable model } \\
\text { parameters }\end{array}$ & Values & $\boldsymbol{R}^{2}$ & $\chi^{2}$ \\
\hline \multicolumn{5}{|l|}{ Methylene blue } \\
\hline \multirow[t]{2}{*}{ Langmuir } & $q_{\max }$ & 106.32 & 0.965 & 0.00075 \\
\hline & $K_{\mathrm{ad}}$ & 0.0939 & & \\
\hline \multirow[t]{2}{*}{ Freundlich } & $K_{\mathrm{f}}$ & 23.093 & 0.923 & 0.00164 \\
\hline & $1 / n_{\mathrm{F}}$ & 0.333 & & \\
\hline \multirow[t]{3}{*}{ Langmuir-Freundlich } & $q_{\max }$ & 93.122 & 0.973 & 0.00057 \\
\hline & $K_{\mathrm{LF}}$ & 0.1229 & & \\
\hline & $\beta_{L F}$ & 1.593 & & \\
\hline \multicolumn{5}{|l|}{ Methyl orange } \\
\hline \multirow[t]{2}{*}{ Langmuir } & $q_{\max }$ & 210.0 & 0.9077 & 0.056 \\
\hline & $K_{\mathrm{ad}}$ & 0.80 & & \\
\hline \multirow[t]{2}{*}{ Freundlich } & $K_{\mathrm{f}}$ & 78.51 & 0.912 & 0.00258 \\
\hline & $1 / n_{\mathrm{F}}$ & 0.364 & & \\
\hline \multirow[t]{3}{*}{ Langmuir-Freundlich } & $q_{\max }$ & 217.97 & 0.989 & 0.000326 \\
\hline & $K_{\mathrm{LF}}$ & 0.4828 & & \\
\hline & $\beta_{L F}$ & 1.259 & & \\
\hline \multicolumn{5}{|l|}{ Malachite Green } \\
\hline \multirow[t]{2}{*}{ Langmuir } & $q_{\max }$ & 59.24 & 0.980 & 0.0041 \\
\hline & $K_{\mathrm{ad}}$ & 0.07 & & \\
\hline \multirow[t]{2}{*}{ Freundlich } & $K_{\mathrm{f}}$ & 9.67 & 0.928 & 0.000675 \\
\hline & $1 / n_{\mathrm{F}}$ & 0.426 & & \\
\hline \multirow[t]{3}{*}{ Langmuir-Freundlich } & $q_{\max }$ & 49.57 & 0.999 & 0.0000076 \\
\hline & $K_{\mathrm{LF}}$ & 0.109 & & \\
\hline & $\beta_{L F}$ & 1.401 & & \\
\hline
\end{tabular}



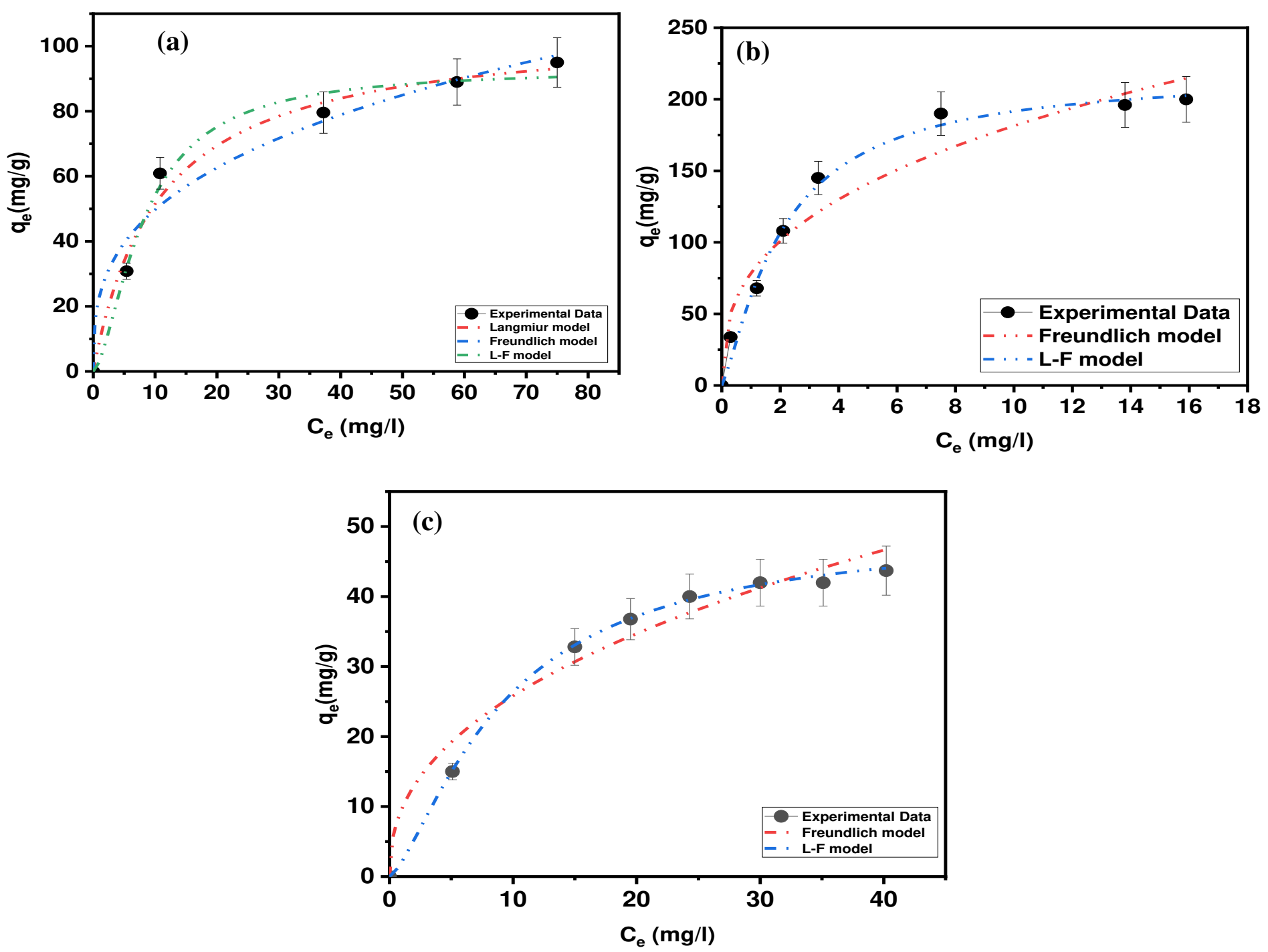

Fig. 16. Experimental adsorption isotherm data from the ternary system for (a) MB and (b) MO and MG dyes on the LDH fitted using the two-parameter isotherm.

\subsubsection{Kinetic studies}

The equilibrium time is considered one of the important factor that effect on the cost and applicability of the adsorption process. Several experiments happened at different time to investigated the equilibrium time of the adsorption process. After that fitting the obtained data to three kinetic models. Figure S2 shows the effect of the time on the adsorption process of MO solution (pH 7) $30 \mathrm{mg} / \mathrm{L}$ onto $\mathrm{Zn}-\mathrm{Fe} \mathrm{LDH}(0.01 \mathrm{mg} / 50 \mathrm{ml})$ at $30 \pm 0.5^{\circ} \mathrm{C}$. We observed from Fig. S2 the adsorption of MO happened with fast rate during the first $20 \mathrm{~min}$, then the rate of adsorption decreased until the equilibrium is achieved within $90 \mathrm{~min} . R^{2}$, we found the pseudo- 
first order, pseudo-second order and Avirma were the best fit kinetic models with $R^{2}=0.997$ (Table 6).

Table 6. Kinetic model parameters $\left(\mathrm{MO}^{+}: 30 \mathrm{mg} / \mathrm{L}\right.$; Zn-Fe LDH: $\left.0.01 \mathrm{mg} / 50 \mathrm{ml}\right)$.

\begin{tabular}{lll}
\hline Kinetic models & Parameters & Values \\
\hline Pseudo first order & $K_{1}$ & 0.018 \\
& $\mathrm{q}_{\mathrm{e}}$ Exp $(\mathrm{mg} / \mathrm{g})$ & 34.90 \\
& $\mathrm{q}_{\mathrm{e}}$ Calc $(\mathrm{mg} / \mathrm{g})$ & 34.24 \\
& $\mathrm{R}^{2}$ & 0.997 \\
Pseudo second order & $K_{2}$ & 1.03 \\
& $\mathrm{q}_{\mathrm{e}}$ Exp $(\mathrm{mg} / \mathrm{g})$ & 34.90 \\
& $\mathrm{q}_{\mathrm{e}}$ Calc $(\mathrm{mg} / \mathrm{g})$ & 34.24 \\
$\mathrm{R}^{2}$ & 0.997 \\
Avrami & $\mathrm{q}_{\mathrm{e}}$ Exp $(\mathrm{mg} / \mathrm{g})$ & 34.90 \\
& $\mathrm{q}_{\mathrm{e}}$ Calc $(\mathrm{mg} / \mathrm{g})$ & 34.24 \\
& $\mathrm{~K}_{\mathrm{av}}$ & 1.814 \\
& $n_{\mathrm{av}}$ & 1.714 \\
$\mathrm{R}^{2}$ & 0.997 \\
\hline
\end{tabular}

\subsubsection{Photocatalytic degradation}

As we all recognized that light ray absorption by the photocatalyst, the separation of the photoelectrons, and holes are important factors during the photocatalytic interaction. According to the above experimental result data, the proposed photodegradation mechanism of $\mathrm{Zn}-\mathrm{Fe} \mathrm{LDH}$ can be illustrated that LDH can absorb visible light rays because of the narrow band gap of 1.765 $\mathrm{eV}$. Under the visible light irradiation, the electrons in the valence band of LDH can be inspired to the conduction band, leaving the holes in the valence band. The structure of LDH can effectively restrain the recombination of photoelectrons and holes to improve photocatalytic activity. The holes left in the valence band of LDH can more easily induce the formation of hydroxyl radicals $(\bullet \mathrm{OH})$ from $\mathrm{OH}$ groups [54] absorbed on the surface. Besides, the electrons passed by LDH are scavenged by the absorbed molecular oxygen $\left(\mathrm{O}_{2}\right)$ to form $\mathrm{O}_{2}{ }^{-}$radicals. These radical groups of $\bullet \mathrm{OH}$ and $\mathrm{O}_{2}{ }^{-}$will result in the decomposition of MO. The effect of initial MO concentration on photodegradation efficiency had been achieved by varying the initial MO 
concentration from 10 and $20 \mathrm{mg} \mathrm{L}^{-1}$ with other parameters such as catalyst concentration, reaction temperature and $\mathrm{pH}$ value remaining constant, and the result is shown in Fig. 17. It could be shown that the photodegradation efficiency decreases with an increase in the initial concentration of MO. The assumed reason is that equilibrium adsorption of reactants on the surface sites of catalyst increases with the MO concentration and with the increase of the initial concentration of MO, the dye molecules absorbed the light much more than the catalyst did, which is thought to have an inhibitive effect on the photodegradation process, and so the rate of photocatalytic reaction decreases [55].
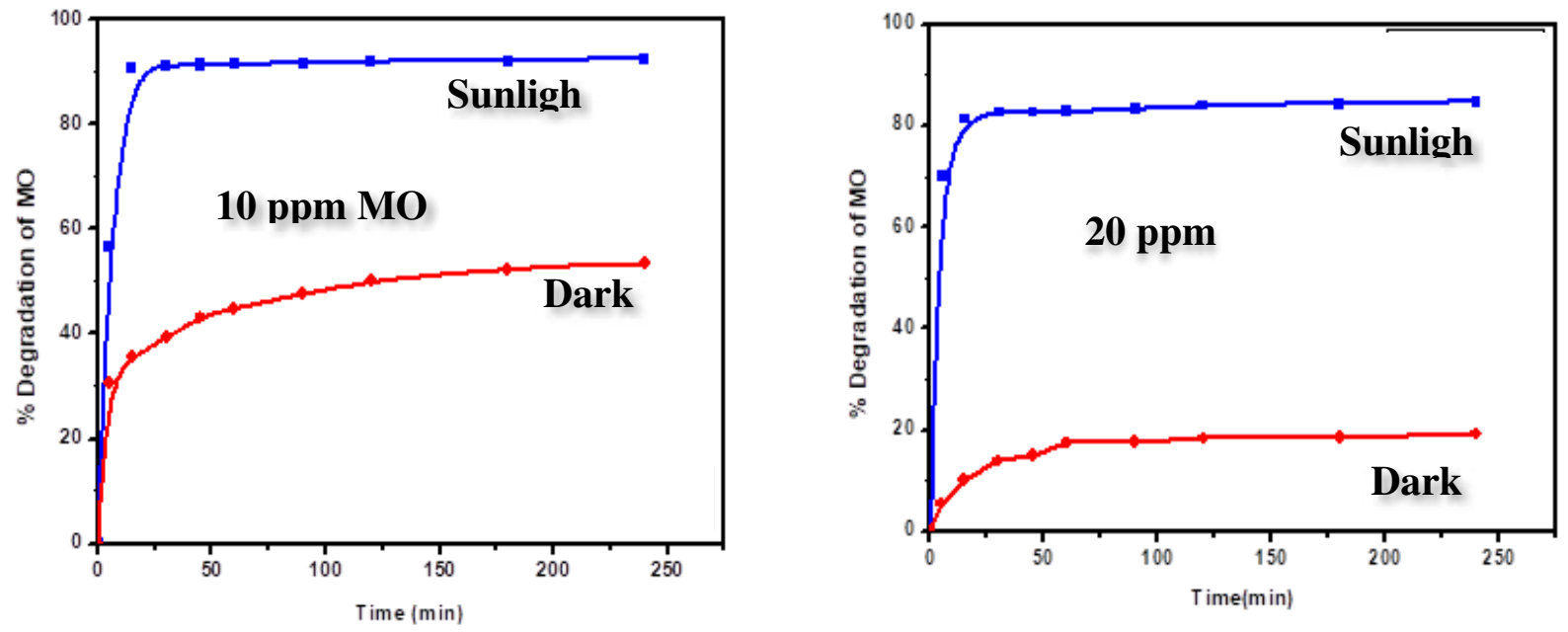

Fig. 17 influence of the Sunlight irradiations on the degradation efficiency for MO [10 and 20ppm, respectively] over $\mathrm{Zn}-\mathrm{Fe} \mathrm{LDH}$ at different irradiation intervals.

\subsection{Monte Carlo (MC) simulation}

To understand the interactions between the dyes and LDH surface, MC study was performed using Zn-Fa LDH (001) and (010) planes. The lowest-energy structures between the studied adsorbates (MO, MB, and MG) and the Zn-Fa LDH (001) and (010) surfaces as obtained from the MC simulations are shown in Figs. (18-19). The studied dyes consist of hydrogen-bonding acceptor atoms (N, O, and $\mathrm{S}$ atoms). Therefore, they may form either intermolecular hydrogen bonds (HBs) with the hydroxyl hydrogen atoms on the LDH surface, or coordinate bonds with the $\mathrm{Zn}$ or Fe actions. The former interactions can be explored by using the (001) surface, while the latter interactions can be viewed by using the (010) and (100) model, respectively. As shown in Fig.16, hydrogen-bonding acceptor atoms of $\mathrm{MO}$ and $\mathrm{MB}$ were formed intermolecular $\mathrm{HBs}$ 
with the hydroxyl hydrogen atoms on the (001) surface. The MO molecule formed the HBs thru the sulfonic oxygens (two oxygens out of the three oxygens) and the three nitrogen atoms. While the MB molecule formed HBs with the LDH hydroxyl groups via the aromatic sulfur and nitrogen atoms. In the case of MG, there is no HBs were observed. The adsorption of MO molecule on the LDH (010) surface displayed that the benzene-1-sulfonate moiety was located between two LDH layer as given in Fig 19 (a) and sulfonic oxygens were formed HBs with the hydroxyl hydrogens of both layers. A diazinyl-moiety nitrogen atom was found to form HB with hydroxyl hydrogen of one LDH layer. A cation- $\pi$ interaction was observed between $\mathrm{Zn}$ cation and the phenyl group as shown in that figure. Additionally, the nitrogen atom of the dimethylamino group was found to be located at a distance of $2.51 \AA$ from a Fe atom, indicating a coordination bond might be formed between them. In the case of $\mathrm{MB}$, the aromatic nitrogen formed HBs with hydroxyl hydrogen of two LDH layers, as shown in Fig. 19 (b). It was found that the MG does not form hydrogen bonds with the LDH (010) surface. The adsorption energies of MO, MB, and MG on the (001) Zn-Fe LDH surface were $-126.8,-80.25$, and $-79.2 \mathrm{kcal} \cdot \mathrm{mol}^{-1}$, and on the (010) Zn-Fe LDH surface were $-140.2,-100.4$, and $-96.7 \mathrm{kcal} \cdot \mathrm{mol}^{-1}$, respectively. This obtained trend agrees with the experimental adsorption capacities of the studied dyes on the Zn-Fe LDH.

(a) Top
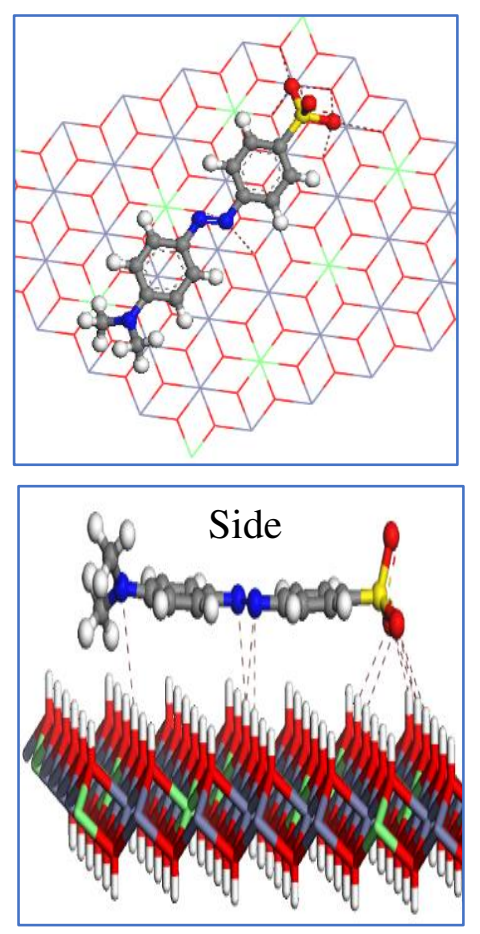

(b) Top
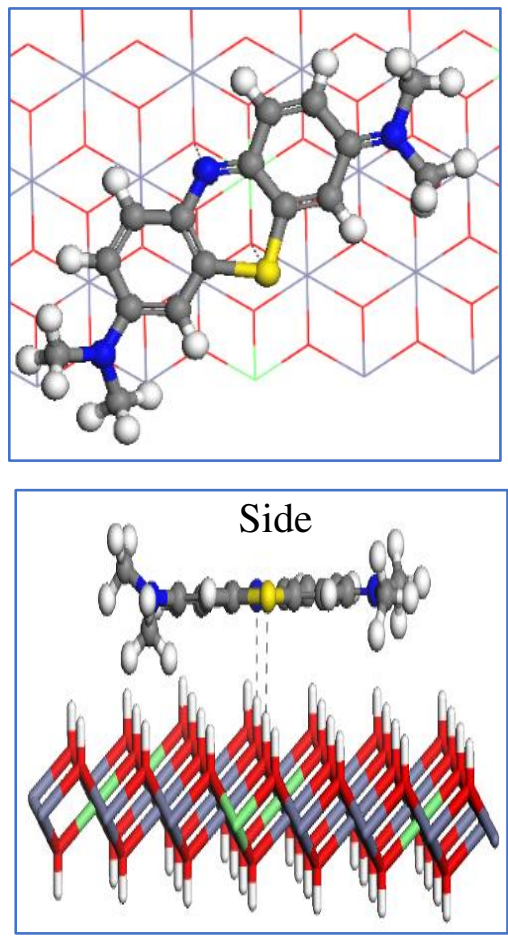

(c) Top
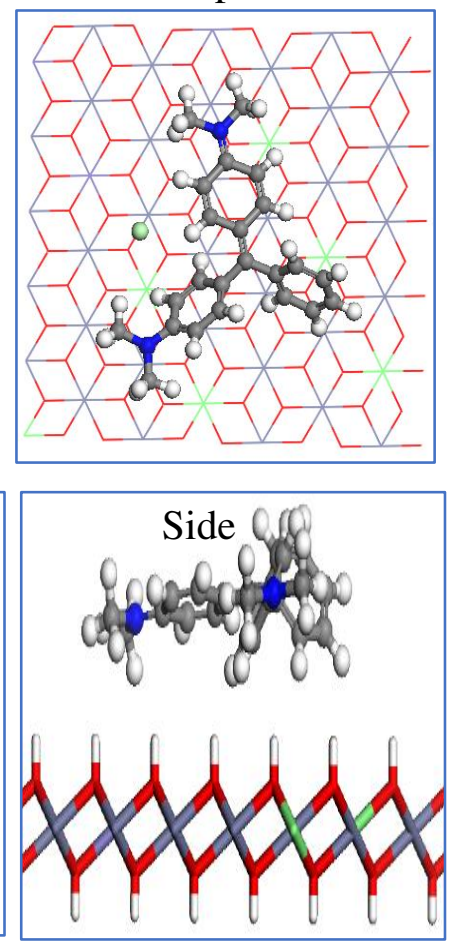
Fig. 18. The adsorption of MO (a), MB (b), and MG (c) molecules on the Zn-Fe LDH (001) surface.
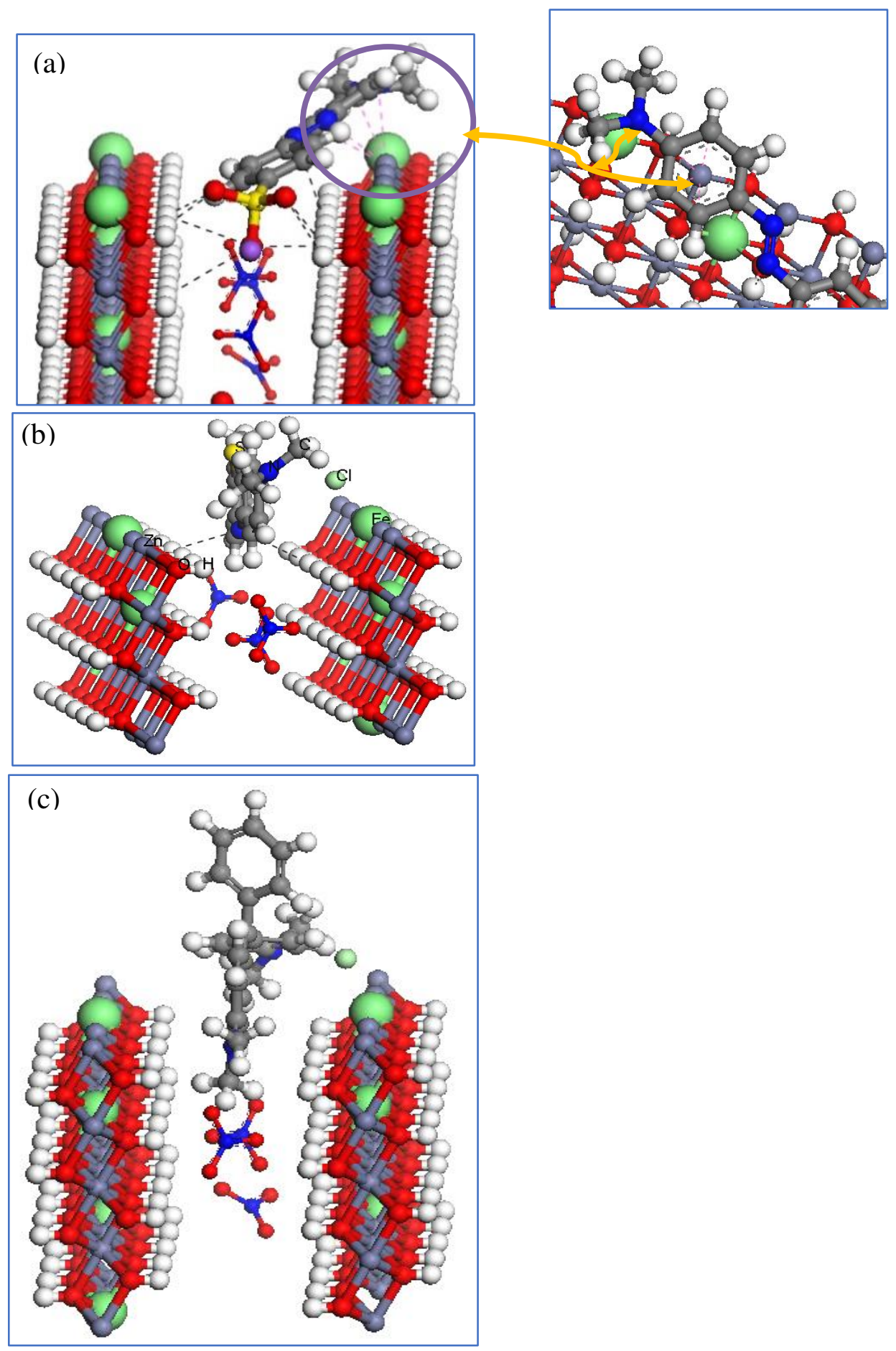
Fig. 19. The adsorption of MO (a), MB (b), and MG (c) molecules on the Zn-Fe LDH (010) surface.

\section{Conclusions}

In this research, a coprecipitation method was applied to synthesize $\mathrm{Zn}-\mathrm{Fe}-\mathrm{LDH}$, then the $\mathrm{Zn}-$ Fe-LDH was used for dye adsorption in single and ternary systems after investigating the structure of the prepared material using physical and chemical methods. For the single system, the maximum adsorption capacities were 230.68, 133.29, and $57.34 \mathrm{mg} / \mathrm{g}$ for $\mathrm{MO}, \mathrm{MB}$, and $\mathrm{MG}$, respectively; for the ternary solution, the respective values were $217.97,93.122$, and $49.57 \mathrm{mg} / \mathrm{g}$. Experimental isotherm data fitted well with nonlinear isotherm models. Furthermore, pseudofirst-order, pseudo-second-order, and Avrami models described the adsorption kinetic data for MO, demonstrating chemisorption and physisorption properties. The optimum $\mathrm{pH}$ was 7, 9, and 6 for $\mathrm{MO}, \mathrm{MB}$, and MG, respectively. The adsorption mechanisms were investigated for dyes through XRD and FT-IR analyses and Monte Carlo simulation. Moreover, LDH proved that it could be applied as a photocatalyst for dye-polluted water.

*Competing interests

The authors confirm no competing interests

\section{References}

1) P. Faria, J. Orfao, M. Pereira, Adsorption of anionic and cationic dyes on activated carbons with different surface chemistries, Water Research, 38 (2004) 2043-2052.

2) J. Wang, M. Gao, T. Shen, M. Yu, Y. Xiang, J. Liu, Insights into the efficient adsorption of rhodamine B on tunable organo-vermiculites, Journal of Hazardous Materials, 366 (2019) 501-511. 
3) S. Xu, X. Niu, Z. Hou, C. Gao, J. Lu, Y. Pang, M. Fang, Y. Lu, Y. Chen, K.J.J.o.h.m. Joshy, A multifunctional gelatine-quaternary ammonium copolymer: An efficient material for reducing dye emission in leather tanning process by superior anionic dye adsorption, Journal of Hazardous Materials 383 (2020) 121142.

4) F. Pourebrahim, M. Ghaedi, K. Dashtian, F. Heidari, S.J.U.s. Kheirandish, Simultaneous removing of $\mathrm{Pb} 2+$ ions and alizarin red $\mathrm{S}$ dye after their complexation by ultrasonic waves coupled adsorption process: spectrophotometry detection and optimization study, Ultrasonics Sonochemistry 35 (2017) 51-60.

5) M. El Haddad, A. Regti, M.R. Laamari, R. Slimani, R. Mamouni, S. El Antri, S.J.J.o.t.T.I.o.C.E. Lazar, Calcined mussel shells as a new and eco-friendly biosorbent to remove textile dyes from aqueous solutions, Journal of the Taiwan Institute of Chemical Engineers 45 (2014) 533-540.

6) G. Crini, P.-M.J.P.i.p.s. Badot, Application of chitosan, a natural aminopolysaccharide, for dye removal from aqueous solutions by adsorption processes using batch studies: A review of recent literature, Progress in Polymer Science 33 (2008) 399-447.

7) T.A. Khan, V.V. Singh, D. Kumar, Removal of some basic dyes from artificial textile wastewater by adsorption on Akash Kinari coal, CSIR, 2004, 63, 355-364.

8) A. Giwa, M. Oladipo, K.J.J.o.C. Abdulsalam, P. Research, Adsorption of Rhodamine B from single, binary and ternary dye systems using sawdust of Parkia biglobosa as adsorbent: isotherm, kinetics and thermodynamics studies, Journal of Chemical and Pharmaceutical Research, 2015. 7, 454-475.

9) E. Eren, B.J.D. Afsin, Pigments, Investigation of a basic dye adsorption from aqueous solution onto raw and pre-treated sepiolite surfaces, Dyes and Pigments 73 (2007) 162167.

10) M.M. Salleh, D. Mahmoud, E.J.J.o.A.S. Al-Maamary, E. Research, Adsorption of basic dye from aqueous solution using mixture of agricultural solid wastes (Maw): isotherm, kinetic studies and process design, Journal of Advanced Science and Engineering Research 1 (2011) 76-97.

11) S. Senthilkumaar, P. Kalaamani, K. Porkodi, P. Varadarajan, C.J.B.t. Subburaam, Adsorption of dissolved reactive red dye from aqueous phase onto activated carbon prepared from agricultural waste, Bioresource Technology 97 (2006) 1618-1625. 
12) D. Robati, M. Rajabi, O. Moradi, F. Najafi, I. Tyagi, S. Agarwal, V.K.J.J.o.M.L. Gupta, Kinetics and thermodynamics of malachite green dye adsorption from aqueous solutions on graphene oxide and reduced graphene oxide, Journal of Molecular Liquids 214 (2016) 259-263.

13) M.D.G. de Luna, E.D. Flores, D.A.D. Genuino, C.M. Futalan, M.-W.J.J.o.t.T.i.o.c.e. Wan, Adsorption of Eriochrome Black T (EBT) dye using activated carbon prepared from waste rice hulls-Optimization, isotherm and kinetic studies, Journal of the Taiwan institute of chemical engineers 44 (2013) 646-653.

14) G.Y.A. El-Reesh, A.A. Farghali, M. Taha, R.K. Mahmoud, Novel synthesis of Ni/Fe layered double hydroxides using urea and glycerol and their enhanced adsorption behavior for Cr (VI) removal, Scientific reports, 10 (2020) 1-20.

15) R. Zhang, Y. Ai, Z. Lu, Application of Multifunctional Layered Double Hydroxides for Removing Environmental Pollutants: Recent Experimental and Theoretical Progress, Journal of Environmental Chemical Engineering, (2020) 103908.

16) J.W. Boclair, P.S. Braterman, Layered double hydroxide stability. 1. Relative stabilities of layered double hydroxides and their simple counterparts, Chemistry of Materials, 11 (1999) 298-302.

17) S.M. Mahgoub, M.R. Shehata, F.L.A. El-Ela, A. Farghali, A. Zaher, R.K. Mahmoud, Sustainable waste management and recycling of $\mathrm{Zn}-\mathrm{Al}$ layered double hydroxide after adsorption of levofloxacin as a safe anti-inflammatory nanomaterial, RSC Advances, 10 (2020) 27633-27651.

18) A. Chithambararaj, B. Winston, N. Sanjini, S. Velmathi, A.C.J.J.o.N. Bose, Nanotechnology, Band gap tuning of h-MoO3 nanocrystals for efficient visible light photocatalytic activity against methylene blue dye, Journal of Nanoscience and Nanotechnology 15 (2015) 4913-4919.

19) L. Ge, W. Wang, Z. Peng, F. Tan, X. Wang, J. Chen, X. Qiao, Facile fabrication of Fe@ $\mathrm{MgO}$ magnetic nanocomposites for efficient removal of heavy metal ion and dye from water, Powder Technology, 326 (2018) 393-401.

20) P. Mohammadi, H. Sheibani, Evaluation, of the bimetallic photocatalytic performance of Resin-Au-Pd nanocomposite for degradation of parathion pesticide under visible light, Polyhedron, 170 (2019) 132-137. 
21) M.-Y. Xu, H.-L. Jiang, Z.-W. Xie, Z.-T. Li, D. Xu, F.-A.J.J.o.t.T.I.o.C.E. He, Highly efficient selective adsorption of anionic dyes by modified $\beta$-cyclodextrin polymers, Journal of the Taiwan Institute of Chemical Engineers 108 (2020) 114-128.

22) A. Zaher, M. Taha, A.A. Farghali, R.K. Mahmoud, Zn/Fe LDH as a clay-like adsorbent for the removal of oxytetracycline from water: combining experimental results and molecular simulations to understand the removal mechanism, Environmental Science and Pollution Research, (2020) 1-14.

23) P. Wongkrua, T. Thongtem, S.J.J.o.N. Thongtem, Synthesis of h-and $\alpha-\mathrm{MoO} 3$ by refluxing and calcination combination: Phase and morphology transformation, photocatalysis, and photosensitization, Journal of Nanomaterials 2013 (2013).

24) M. Fox, Optical properties of solids, in, American Association of Physics Teachers, 2002.

25) S.A. Khan, F. Al-Hazmi, S. Al-Heniti, A. Faidah, A.J.c.a.p. Al-Ghamdi, Effect of cadmium addition on the optical constants of thermally evaporated amorphous $\mathrm{Se}-\mathrm{S}-\mathrm{Cd}$ thin films, current applied physics, 10 (2010) 145-152.

26) F. Nekouei, H. Kargarzadeh, S. Nekouei, F. Keshtpour, A.S.H.J.A. Makhlouf, b. chemistry, Efficient method for determination of methylene blue dye in water samples based on a combined dispersive solid phase and cloud point extraction using $\mathrm{Cu}(\mathrm{OH}) 2$ nanoflakes: central composite design optimization, Analytical and Bioanalytical Chemistry 409 (2017) 1079-1092.

27) G. Fan, F. Li, D.G. Evans, X. Duan, Catalytic applications of layered double hydroxides: recent advances and perspectives, Chemical Society Reviews, 43 (2014) 7040-7066.

28) A.K. Rappe, W.A. Goddard III, Charge equilibration for molecular dynamics simulations, The Journal of Physical Chemistry, 95 (1991) 3358-3363.

29) O. Rahmanian, S. Amini, M.J.J.o.M.L. Dinari, Preparation of zinc/iron layered double hydroxide intercalated by citrate anion for capturing Lead (II) from aqueous solution, Journal of Molecular Liquids 256 (2018) 9-15.

30) H. Lu, Z. Zhu, H. Zhang, J. Zhu, Y.J.C.E.J. Qiu, Simultaneous removal of arsenate and antimonate in simulated and practical water samples by adsorption onto $\mathrm{Zn} / \mathrm{Fe}$ layered double hydroxide, Chemical Engineering Journal 276 (2015) 365-375.

31) L. Li, J. Iqbal, Y. Zhu, P. Zhang, W. Chen, A. Bhatnagar, Y. Du, Chitosan/Aghydroxyapatite nanocomposite beads as a potential adsorbent for the efficient removal of 
toxic aquatic pollutants, International journal of biological macromolecules, 120 (2018) 1752-1759.

32) S. Zhang, Z. Liu, D. Chen, Z. Guo, M. Ruan, Oxygen vacancies engineering in TiO2 homojunction/ZnFe-LDH for enhanced photoelectrochemical water oxidation, Chemical Engineering Journal, (2020) 125101.

33) H. Lu, T. Lu, H. Zhang, Y. Qiu, D. Yin, Z. Zhu, Enhanced adsorption performance of aspartic acid intercalated Mg-Zn-Fe-LDH materials for arsenite, Dalton Transactions, 47 (2018) 4994-5004.

34) M. Gilanizadeh, B. Zeynizadeh, Synthesis and characterization of the immobilized Ni$\mathrm{Zn}-\mathrm{Fe}$ layered double hydroxide (LDH) on silica-coated magnetite as a mesoporous and magnetically reusable catalyst for the preparation of benzylidenemalononitriles and bisdimedones (tetraketones) under green conditions, New Journal of Chemistry, 42 (2018) 8553-8566.

35) N.K. Gupta, M. Saifuddin, S. Kim, K.S. Kim, Microscopic, spectroscopic, and experimental approach towards understanding the phosphate adsorption onto $\mathrm{Zn}-\mathrm{Fe}$ layered double hydroxide, Journal of Molecular Liquids, 297 (2020) 111935.

36) S.A.B. Asif, S.B. Khan, A.M. Asiri, Efficient solar photocatalyst based on cobalt oxide/iron oxide composite nanofibers for the detoxification of organic pollutants, Nanoscale research letters, 9 (2014) 510.

37) S. Naseem, B. Gevers, R. Boldt, F.J.W. Labuschagné, A. Leuteritz, Comparison of transition metal $(\mathrm{Fe}, \mathrm{Co}, \mathrm{Ni}, \mathrm{Cu}$, and $\mathrm{Zn})$ containing tri-metal layered double hydroxides (LDHs) prepared by urea hydrolysis, RSC advances, 9 (2019) 3030-3040.

38) K. Nejati, A.R. Akbari, S. Davari, K. Asadpour-Zeynali, Z. Rezvani, Zn-Fe-layered double hydroxide intercalated with vanadate and molybdate anions for electrocatalytic water oxidation, New Journal of Chemistry, 42 (2018) 2889-2895.

39) S. Zhu, S. Jiao, Z. Liu, G. Pang, S.J.E.S.N. Feng, High adsorption capacity for dye removal by CuZn hydroxyl double salts, Chemical Engineering Journal 1 (2014) 172180.

40) K. Al-Ammar, A. Hashim, M.J.C.M.E. Husaien, Synthesis and study of optical properties of (PMMA-CrCl2) composites, Chem. Mater. Eng 1 (2013) 85-87. 
41) A.K. Sharma, A.J.J.o.P.D.A.P. Kumar, Nonlinear gain of a millimetre wave antenna array mounted on a re-entry vehicle, Journal of Physics D: Applied Physics 40 (2007) 2033.

42) S. Ramalingam, K.J. Sreeram, J.R. Rao, B.U. Nair, Hybrid composites: amalgamation of proteins with polymeric phenols as a multifunctional material for leather processing, RSC Advances, 5 (2015) 33221-33232.

43) H.A. Younes, R. Khaled, H.M. Mahmoud, H.F. Nassar, M.M. Abdelrahman, F.I.A. ElEla, M. Taha, Computational and experimental studies on the efficient removal of diclofenac from water using $\mathrm{ZnFe}$-layered double hydroxide as an environmentally benign absorbent, Journal of the Taiwan Institute of Chemical Engineers, 102 (2019) 297-311.

44) H.-J. Choi, Use of methyl esterified eggshell membrane for treatment of aqueous solutions contaminated with anionic sulfur dye, Water Science and Technology, 76 (2017) 2638-2646.

45) R.J. Umpleby, S.C. Baxter, Y. Chen, R.N. Shah, K.D. Shimizu, Characterization of molecularly imprinted polymers with the Langmuir- Freundlich isotherm, Analytical chemistry, 73 (2001) 4584-4591.

46) M. Nagpal, R. Kakkar, Selective adsorption and separation of toxic cationic dyes using hierarchically porous SDBS modified vaterite microspheres (Hr-SMV), Journal of Physics and Chemistry of Solids, 146 (2020) 109598.

47) N. Florence, H. Naorem, Dimerization of methylene blue in aqueous and mixed aqueous organic solvent: A spectroscopic study, Journal of Molecular Liquids, 198 (2014) 255258.

48) L. Ai, C. Zhang, L. Meng, Adsorption of methyl orange from aqueous solution on hydrothermal synthesized $\mathrm{Mg}-\mathrm{Al}$ layered double hydroxide, Journal of Chemical \& Engineering Data, 56 (2011) 4217-4225.

49) J. Ma, J. Ding, L. Yu, L. Li, Y. Kong, S. Komarneni, BiOCl dispersed on NiFe-LDH leads to enhanced photo-degradation of Rhodamine B dye, Applied Clay Science, 109 (2015) 76-82.

50) A.S. Mohamed, M.R. Abukkhadra, E.A. Abdallah, A.M. El-Sherbeeny, R.K. Mahmoud, The photocatalytic performance of silica fume based Co3O4/MCM-41 green 
nanocomposite for instantaneous degradation of Omethoate pesticide under visible light, Journal of Photochemistry and Photobiology A: Chemistry, 392 (2020) 112434. 


\section{Supplementary Files}

This is a list of supplementary files associated with this preprint. Click to download.

- supplementaryfile.docx 